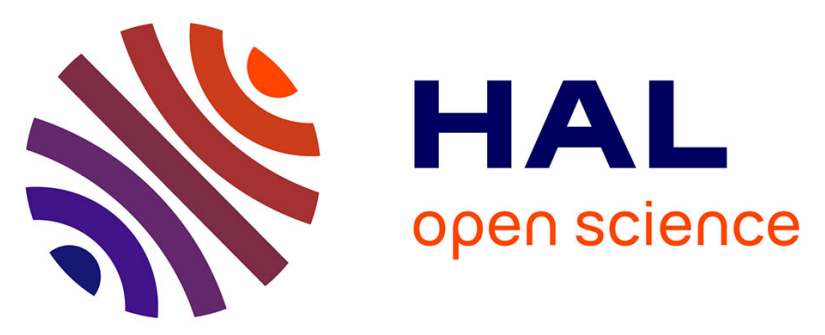

\title{
CONTEXTE GÉOMORPHOLOGIQUE, CHRONOSTRATIGRAPHIQUE ET PALÉOENVIRONNEMENTAL DES SITES MÉSOLITHIQUES ET PALÉOLITHIQUES DE WARLUIS DANS LA VALLÉE DU THÉRAIN (OISE, FRANCE)
}

Sylvie Coutard, Thierry Ducrocq, Nicole Limondin-Lozouet, Anne Bridault, Chantal Leroyer, Gisèle Allenet, Jean-François Pastre

\section{To cite this version:}

Sylvie Coutard, Thierry Ducrocq, Nicole Limondin-Lozouet, Anne Bridault, Chantal Leroyer, et al.. CONTEXTE GÉOMORPHOLOGIQUE, CHRONOSTRATIGRAPHIQUE ET PALÉOENVIRONNEMENTAL DES SITES MÉSOLITHIQUES ET PALÉOLITHIQUES DE WARLUIS DANS LA VALLÉE DU THÉRAIN (OISE, FRANCE). Quaternaire, 2010, 21 (4), pp.357-384. 10.4000/quaternaire.5702 . halshs-00564184

\section{HAL Id: halshs-00564184 \\ https://shs.hal.science/halshs-00564184}

Submitted on 22 Dec 2017

HAL is a multi-disciplinary open access archive for the deposit and dissemination of scientific research documents, whether they are published or not. The documents may come from teaching and research institutions in France or abroad, or from public or private research centers.
L'archive ouverte pluridisciplinaire HAL, est destinée au dépôt et à la diffusion de documents scientifiques de niveau recherche, publiés ou non, émanant des établissements d'enseignement et de recherche français ou étrangers, des laboratoires publics ou privés. 


\title{
CONTEXTE GÉOMORPHOLOGIQUE, CHRONOSTRATIGRAPHIQUE ET PALÉOENVIRONNEMENTAL DES SITES MÉSOLITHIQUES ET PALÉOLITHIQUES DE WARLUIS DANS LA VALLÉE DU THÉRAIN (OISE, FRANCE)
}

\author{
Sylvie COUTARD ${ }^{1}$, Thierry DUCROCQ ${ }^{1}$, Nicole LIMONDIN-LOZOUET ${ }^{2}$, \\ Anne BRIDAULT ${ }^{3}$, Chantal LEROYER ${ }^{4}$, Gisèle ALLENET ${ }^{5} \&$ \\ Jean-François PASTRE ${ }^{2}$
}

\begin{abstract}
RÉSUMÉ
Le gisement mésolithique de Warluis (Oise) a été mis au jour dans une gravière couvrant une quarantaine d'hectares de la plaine alluviale du Thérain, un affluent de l'Oise. Plusieurs paléochenaux ont été repérés: un chenal tardiglaciaire à comblement organique et limoneux, des chenaux tourbeux et un chenal de tuf holocène. Une trentaine de concentrations de vestiges lithiques et fauniques ont été fouillées manuellement sur $2400 \mathrm{~m}^{2}$. La séquence sédimentaire la plus représentée sur les sites est une succession: grave de fond weichselienne - sables limoneux blancs - limons sableux organiques - tourbe - limons plastiques peu épais. Deux couches se distinguent généralement dans les limons sableux organiques, l'une plus grise à la base, l'autre plus brune. Des arguments stratigraphiques, archéologiques, malacologiques, palynologiques et des datations radiocarbone permettent d'attribuer un âge Allerød aux limons gris, qui contiennent des industries du Paléolithique final à Federmesser. Sur l'Allerød se superposent directement des apports détritiques plus organiques bruns très bioturbés qui correspondent au Préboréal et au début du Boréal (ce dernier marqué par le développement du gastéropode Discus rotundatus). Ces sédiments contiennent les vestiges mésolithiques. Les tourbes sont présentes sur quasiment toute la carrière sur une épaisseur variable (plusieurs mètres dans les chenaux, quelques centimètres ou absentes sur les points les plus hauts). Les datations obtenues jusqu'à présent convergent pour attribuer un âge boréal et atlantique ancien à cette tourbe qui recouvre l'ensemble des niveaux archéologiques. Les populations mésolithiques se sont installées à proximité de paléochenaux ou sur de petites éminences du fond de vallée. Les premières datations radiocarbone indiquent une succession d'occupations depuis le début de l'Holocène, vers 9900 BP, jusqu'au début du Boréal vers 8800 BP. Les premiers résultats de l'étude archéozoologique témoignent d'une prédation du cerf, du chevreuil et de l'aurochs sur les sites les plus anciens et d'une exploitation qui se réoriente sur le sanglier au début du Boréal. Ceci coïncide avec la densification du couvert végétal et le boisement progressif révélés par l'analyse palynologique et les cortèges malacologiques.
\end{abstract}

Mots-clés : Tardiglaciaire, Holocène ancien, alluvial, Mésolithique, Paléolithique final, Malacofaune, Mammifères, pollen, Nord de la France.

\section{ABSTRACT}

GEOMORPHOLOGICAL, CHRONOSTRATIGRAPHIC AND PALAEOENVIRONMENTAL CONTEXT OF PALAEOLITHIC AND MESOLITHIC SITES AT WARLUIS (THERAIN VALLEY, FRANCE)

Warluis Mesolithic sites were discovered during rescue archaeological excavations in a quarry spread over 40 hectares, located in the Therain alluvial plain (Northern France). Several palaeochannels of Lateglacial and Holocene age are present. The Lateglacial sequence contains organic and silty deposits. Holocene infillings are mainly peaty, except one tufaceous channel. Some 30 concentrations of lithic artefacts and faunal remains have been handdigged over $2400 \mathrm{~m}^{2}$. The most frequent sedimentary sequence is composed of (from bottom to top): weichselian gravel, white silty sands, organic sandy silts, peat, clayey silts. Organic sandy silts are divided into a basal greyish bed and an upper brown horizon. Stratigraphical, archaeological, malacological and palynological arguments together with radiocarbon datings allow to establish an Allerød age for the basal greyish sediment that contains Final Palaeolithic industry. Above the Allerød bed are deposited Preboreal and Boreal brown sediments. Boreal deposits are marked by the development of the gastropod Discus rotundatus. These intensively bioturbated sediments contain Mesolithic artefacts and faunal remains. Peat spreads on almost the whole valley bottom, overlaying all mesolithic settlements. Peat thickness varies from a few meters within channels down to a few centimetres (even absent) on higher places. It is dated from the Boreal to the Early Atlantic. Mesolithic settlements are located on channel banks or on the hummocks in the valley bottom. Radiocarbon datings indicate that many occupations occurred since the Early Holocene (ca 9900 BP) to the Early Boreal (ca 8800 BP). First results of archaeozoological studies show a predation on red deer, roe deer and aurochs on the earliest sites and on wild boar at the beginning of the Boreal. This fits with a gradual afforestation of the area as showed by both malacological and palynological records.

Key-words: Late Glacial, Early Holocene, alluvial deposits, Mesolithic, Latest Palaeolithic, malacofaunas, mammals, pollen, Northern France.

${ }^{1}$ INRAP Nord-Picardie, 518 rue Saint-Fuscien, 80000 Amiens. Courriel : sylvie.coutard@inrap.fr, thierry.ducrocq@inrap.fr

${ }^{2}$ UMR 8591, Laboratoire de Géographie Physique, 1 place A. Briand, 92195 Meudon Cedex.

Courriel: Nicole.Limondin@cnrs-bellevue.fr, Pastre@cnrs-bellevue.fr

${ }^{3}$ Maison de l'Archéologie et de l'Ethnologie, UMR 7041 CNRS, 21 allée de l'Université, 92023 Nanterre Cedex.

Courriel : anne.bridault@mae.u-paris10.fr

${ }^{4}$ MCC, UMR 6566 / CReAAH «Centre de Recherche en Archéologie, Archéosciences, Histoire», Laboratoire «ArchéoSciences», Université de Rennes 1, Campus de Beaulieu, bât. 24-25, CS 74205, F-35042 Rennes Cedex. Courriel: chantal.leroyer@univ-rennes1.fr

${ }^{5}$ INRAP Grand Sud-Ouest, Centre d'activité Les Echoppes, 156, av. Jean Jaurès, F-33600 Pessac. Courriel: gisele.allenet-de-ribemont@inrap.fr 


\section{1 - INTRODUCTION}

Le gisement mésolithique de Warluis, fouillé dans le cadre d'une opération d'archéologie préventive en carrière entre 2001 et 2005, s'avère d'une importance majeure dans l'établissement du cadre chronoculturel des 1500 premières années du Mésolithique (Ducrocq et al., 2008).

Cet article a pour objectif de présenter le contexte géomorphologique, chronostratigraphique et paléoenvironnemental des sites fouillés; l'étude archéologique détaillée sera publiée par ailleurs. Cette approche est primordiale pour comprendre les relations entre l'homme et l'environnement, restituer les différents paysages contemporains des occupations et discuter la qualité taphonomique des sites archéologiques. L'étude s'appuie sur les travaux portant sur l'évolution des fonds de vallée au cours du Tardiglaciaire et de l'Holocène réalisés depuis une vingtaine d'années dans les bassins-versant de la
Somme (Antoine, 1997; Antoine et al., 2000, 2002, 2003) et de la Seine (Pastre et al., 1997, 2000, 2002, 2003).

\section{1 - LOCALISATION GÉOGRAPHIQUE ET GÉOLOGIQUE}

Les sites de Warluis, au lieu-dit «marais de Merlemont», se situent dans la plaine alluviale du Thérain, un affluent de l'Oise s'écoulant du nord-ouest vers le sud-est, à quelques kilomètres à l'aval de Beauvais (fig. 1). La carrière de Merlemont couvre les deux tiers de la largeur du fond de vallée, qui mesure environ un kilomètre. Elle est implantée légèrement à l'aval de la confluence actuelle du Thérain et du Ru de Laversines.

Le Thérain suit un axe parallèle à l'anticlinal du Pays de Bray, le «Synclinal du Thérain» (Blondeau et al., 1970). Au niveau du gisement, la rive droite est façonnée dans les formations tertiaires représentées principale-

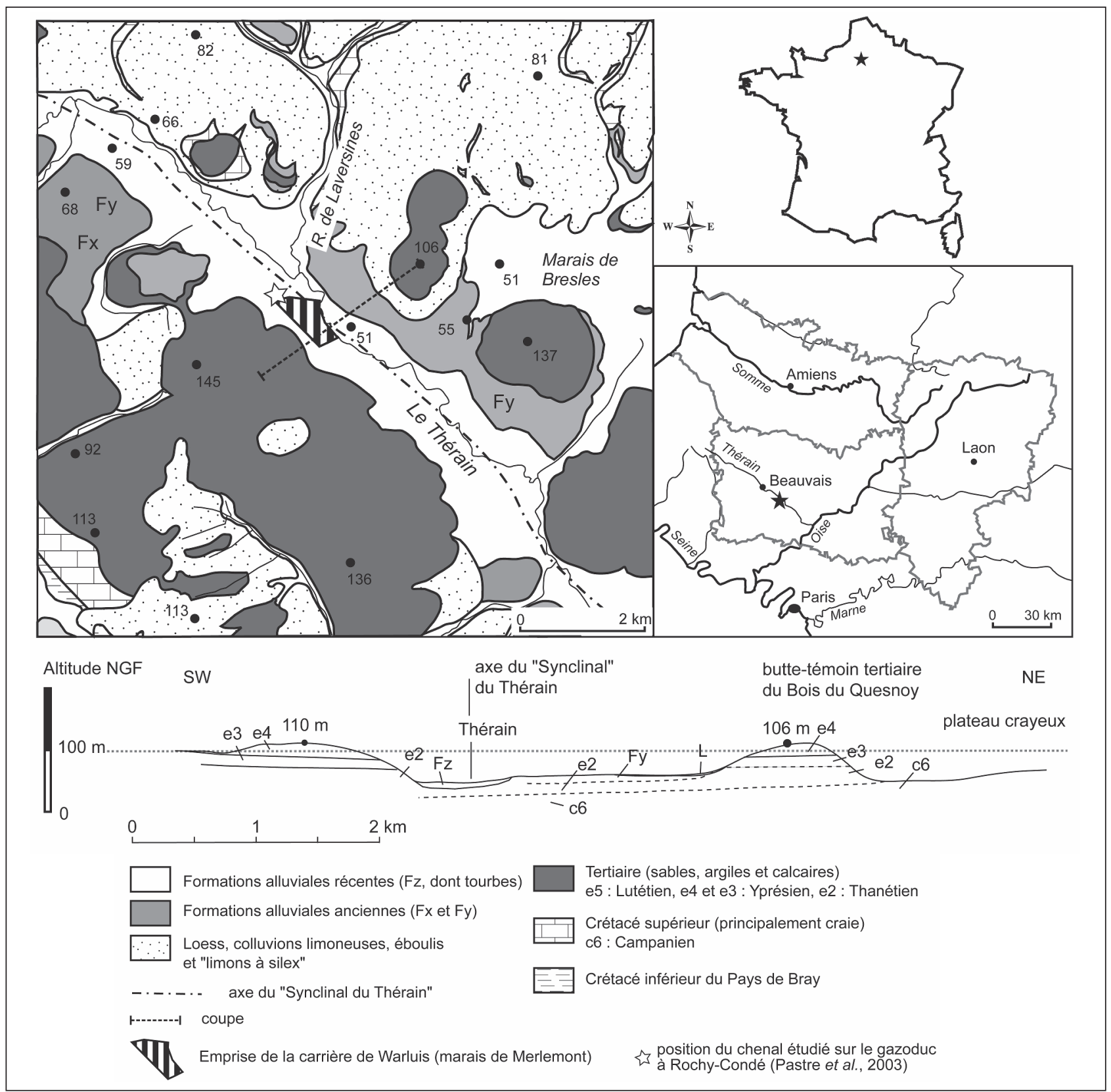

Fig. 1 : Localisation et contexte géologique.

Fig. 1: Location map and geological context. 
ment par des sables, des argiles et des calcaires (Thanétien, Yprésien, Lutétien). La rive gauche se raccorde au plateau crayeux crétacé par un versant façonné dans les sables thanétiens qui supporte une terrasse alluviale (Fy). Le plateau crayeux est ici couronné de quelques buttestémoins tertiaires. Le substratum de la vallée au niveau de Warluis n'a pas été vu. Une coupe réalisée d'après la carte géologique (Blondeau et al., 1970) indique qu'il est constitué de sables tertiaires (e2: Sables de Bracheux).

\section{2 - DÉROULEMENT DU DIAGNOSTIC ET DE LA FOUILLE}

Le diagnostic archéologique sur les 45 hectares de la carrière s'est effectué en trois tranches (fig. 2) de 2000 à 2004 sous la direction de T. Ducrocq (INRAP). Un géomorphologue (S. Coutard, INRAP) n'a été présent sur le site de manière régulière qu'à partir d'octobre 2004.

Réalisé à la pelle mécanique, le diagnostic a consisté en tranchées et surtout en sondages ponctuels effectués avec minutie. Les sondages ponctuels permettent de mieux gérer la remontée de la nappe phréatique et de mettre au jour les sites en limitant l'ouverture et donc les destructions. Les sondages ont fait l'objet d'un levé stratigraphique systématique.

Ces phases de diagnostic ont permis d'identifier 10 sites archéologiques, c'est-à-dire des zones riches en vestiges séparées les unes des autres par des zones stériles (fig. 2). Les périodes représentées sont le Mésolithique et le Paléolithique final (Azilien - Federmesser).
Chaque site est constitué d'une ou plusieurs concentrations de vestiges lithiques et de faune. A l'exception du site $\mathrm{X}$ mis en réserve, les gisements ont été fouillés à la main sur environ $2400 \mathrm{~m}^{2}$ au total entre 2001 et 2005 . Les sites ont rarement pu être fouillés intégralement mais des décapages à la pelle mécanique ont permis d'explorer près d'un hectare supplémentaire.

Lors de la fouille, une attention particulière a été portée à la position stratigraphique des pièces. Les aspects taphonomiques sont en effet primordiaux dans les sites mésolithiques, en raison d'une dispersion verticale sensible des artefacts d'un même niveau et de la fréquence des réoccupations successives d'un même lieu (Ducrocq, 2001).

\section{3 - MÉTHODES D’ÉTUDE}

L'étude des chenaux n'a pas pu être envisagée du fait de leur destruction rapide par l'exploitation de la carrière, qui s'est poursuivie durant l'intervention archéologique. Une étude palynologique a été menée sur le remplissage d'un chenal passant au milieu du site III (prélèvements en 2001).

Un échantillonnage malacologique a été effectué sur huit profils répartis sur plusieurs sites archéologiques; seuls trois profils ont été étudiés jusqu'à présent. La multiplication des colonnes de prélèvements permet de contrôler l'identification des paramètres environnementaux pertinents au niveau du site par rapport à des signaux plus ponctuels qui pourraient être liés à des conditions très localisées. Par ailleurs, cette multiplicité est associée à la résolution de questionnements archéologiques précis.

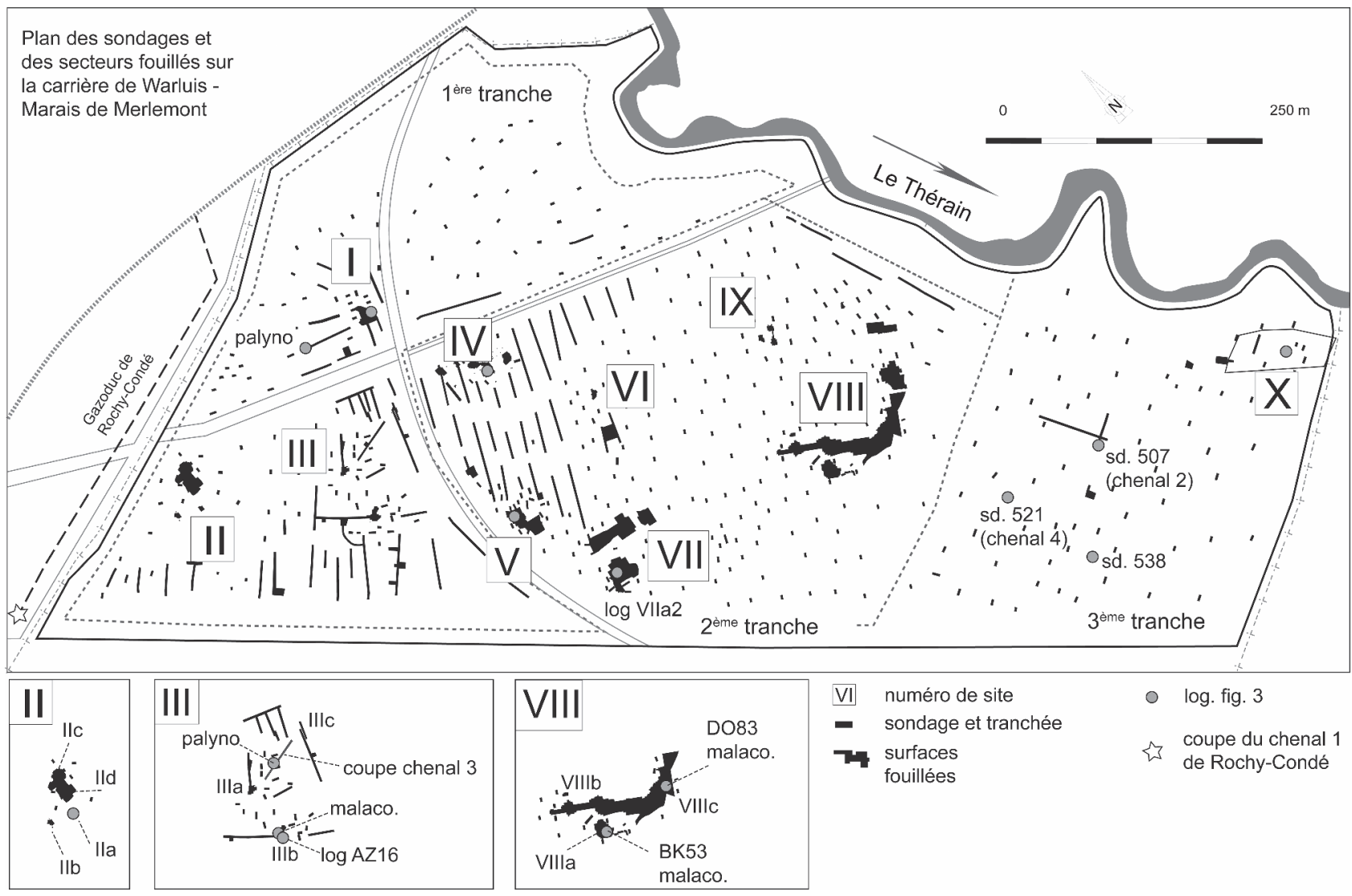

Fig. 2 : Plan des sondages et des fouilles.

Localisation des logs et des profils étudiés avec un zoom sur les sites II, III et VIII.

Fig. 2: Map of boreholes and excavations. 
Quelques échantillons micromorphologiques pour l'étude des sédiments en lame mince ont été prélevés sur quelques profils représentatifs, parfois en association avec les prélèvements malacologiques.

Des datations ${ }^{14} \mathrm{C}$ ont été effectuées sur des ossements et des coquilles de noisettes carbonisées associés sans ambiguïté aux vestiges archéologiques (tab. 1).

\section{2 - PRINCIPALES CARACTÉRISTIQUES MORPHOSÉDIMENTAIRES}

La compilation de l'ensemble des données de sondages et de fouilles permet de proposer des séquences pédosédimentaires synthétiques par zones (fig. 3). Cependant, l'absence quasi-générale de cotes altimétriques précises sur les sondages des phases de diagnostic (levé topographique au GPS, qui implique une marge d'erreur de $\pm 30 \mathrm{~cm}$ sur les altitudes) limite la compréhension de variations latérales de faciès liées à la microtopographie.

Sur l'ensemble de l'emprise diagnostiquée, trois ensembles morpho-sédimentaires principaux peuvent être distingués en fonction de la dilatation de la sédimentation au-dessus de la nappe de fond: les zones hautes (ou dômes) où les limons organiques (limons bruns, Lb, unité $\mathrm{n}^{\circ} 4$ et limons gris, $\mathrm{Lg}$, unité $\mathrm{n}^{\circ} 6$ ) sont quasiment absents, les zones basses où la stratigraphie est plus dilatée et les chenaux.

De manière générale on trouve de haut en bas (fig. 3): un horizon de labour (1), des limons argileux plastiques (Lpl - 2), une tourbe ou des limons tourbeux (T, Lt - 3), des limons plus ou moins sableux organiques bruns $(\mathrm{Lb}-4)$ et gris $(\mathrm{Lg}-6)$, des limons sableux ou des sables blanchâtres à jaunâtres (Lsbj - 8), les graviers de fond (Gr - 9). Des limons calcaires blancs (Lcalc - 5) séparent les limons organiques en deux ensembles dans certains secteurs. La sédimentation tourbeuse ( $\mathrm{T}-3)$ occupe la plus grande partie du fond de vallée. Les limons argileux plastiques supérieurs ( $\mathrm{Lpl}$ - 2), bruns à verdâtres, sont peu épais $(20-40 \mathrm{~cm})$, compactés, et livrent des vestiges du Néolithique à la période gallo-romaine.

Une zone très basse où des sédiments organiques (tourbe et limons tourbeux (7) sont conservés sous des limons calcaires blancs (Lcalc - 5) a été en outre repérée au sud de l'emprise; elle ne contient pas de site archéologique.

\section{1 - LA NAPPE DE FOND}

La base de la séquence sédimentaire de fond de vallée est une nappe de fond composée de galets de silex (unité $\mathrm{n}^{\circ} 9$ - Gr), observée dans les sondages et dans l'exploitation. Les silex sont plus ou moins roulés, et parfois encore légèrement branchus bien qu'émoussés pour les blocs les plus gros. Ils sont issus de la craie campanienne du bassin-versant.

Cette nappe de fond forme des dômes, probablement pour une part hérités des écoulements en tresses en contexte périglaciaire (fig. 4). Certains dômes sont recouverts de sables ou de limons blanchâtres. Les sables sont parfois verdâtres (présence de glauconie) car ils sont issus du substratum tertiaire. La profondeur maximale observée du toit de la grave par rapport à la surface du sol est de 3,60 mètres.

\section{2 - LES CHENAUX}

De nombreux paléochenaux traversent la plaine alluviale (fig. 4 et 5). Les chenaux à remplissage tourbeux sont nombreux. Ils sont cartographiés à partir de l'épaisseur maximale de sédimentation (en particulier pour les tourbes, fig. 5) et des indices d'écoulement: bois flottés, alternances organo-minérales, faciès lités.... Les berges sont rarement identifiées en sondages. L'épaisseur maximale de tourbe observée est de $2,50 \mathrm{~m}$.

\section{- le Chenal 1 ou chenal de Rochy-Condé}

Lors de la réalisation du gazoduc du Vexin (suivi par T. Ducrocq en 1999) passant en bordure de la carrière de Merlemont à Rochy-Condé (localisation fig. 1 et log fig. 3), plusieurs paléochenaux ont été repérés sur la largeur de la vallée. L'un d'eux, creusé dans la grave de fond, a révélé un remplissage composé de $10 \mathrm{~cm}$ de limons argileux, de sédiments organo-détritiques (limons plus ou moins organiques parfois lités, comprenant une passée tourbeuse) épais de 1,2 m, recouverts par $0,9 \mathrm{~m}$ de limons calcaires blancs (Pastre et al., 2003).

\section{- le Chenal 2}

Un chenal profond de plus de $2 \mathrm{~m}$ a été repéré dans la carrière de Warluis. La figure 3 montre le relevé du sondage 507, représentatif de son remplissage. La stratigraphie peut être corrélée à celle du chenal 1 grâce à la présence des limons calcaires blancs (Lcalc, unité $\mathrm{n}^{\circ}$ 5)]. Ces derniers séparent une tourbe rousse à bois à la base d'une tourbe noire plus fine au sommet. Ce chenal pourrait être le même qu'à Rochy-Condé avec une phase de dépôts postérieure aux limons calcaires (Lcalc) mieux conservée.

\section{- le Chenal 3}

Un chenal a été étudié de manière détaillée dans le site III (localisation fig. 2, description fig. 6). Il s'agit d'un chenal large de près de $40 \mathrm{~m}$ incisé dans la grave de fond (Gr, n 9).

La première phase de colmatage est représentée par les sables limoneux blancs (Lsbj, $\left.n^{\circ} 8\right)$, faciès largement reconnu dans la carrière, que ce soit dans les zones basses ou sur les zones hautes (site IV, par exemple). Au-dessus se déposent des limons organo-minéraux gris foncé (corrélables à $\mathrm{Lg}, \mathrm{n}^{\circ} 6$ ), puis des limons calcaires blancs (Lcalc, $\mathrm{n}^{\circ} 5$ ) et des limons argileux organo-minéraux gris-bruns (corrélables à $\mathrm{Lb}, \mathrm{n}^{\circ} 4$ ). Les limons calcaires sont cantonnés au centre du chenal et ne remontent pas sur les berges, où les limons bruns $(\mathrm{Lb}, 4)$ semblent reposer directement sur des limons plus gris $(\mathrm{Lg}, 6)$. Les faciès $\mathrm{Lb}$ et $\mathrm{Lg}$ du chenal se raccordent donc bien aux faciès $L g$ et $L b$ observés dans les zones basses. Le colmatage du chenal devient ensuite tourbeux. Les tourbes ( $T$, $\mathrm{n}^{\circ} 3$ ) atteignent $1,20 \mathrm{~m}$ d'épaisseur. La sédimentation tourbeuse est interrompue par une décharge détritique argilo-limoneuse grise épaisse de quelques centimètres 


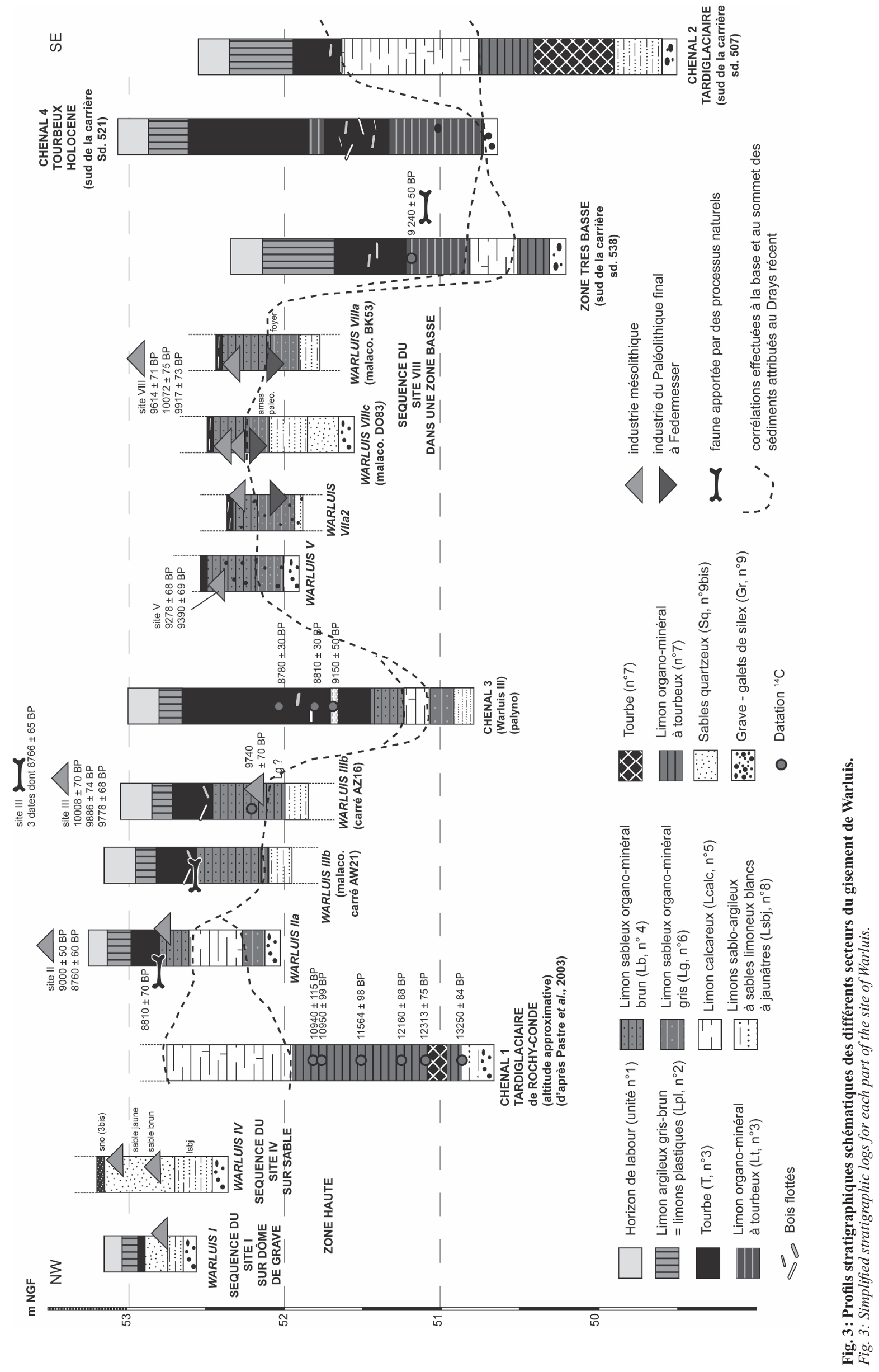




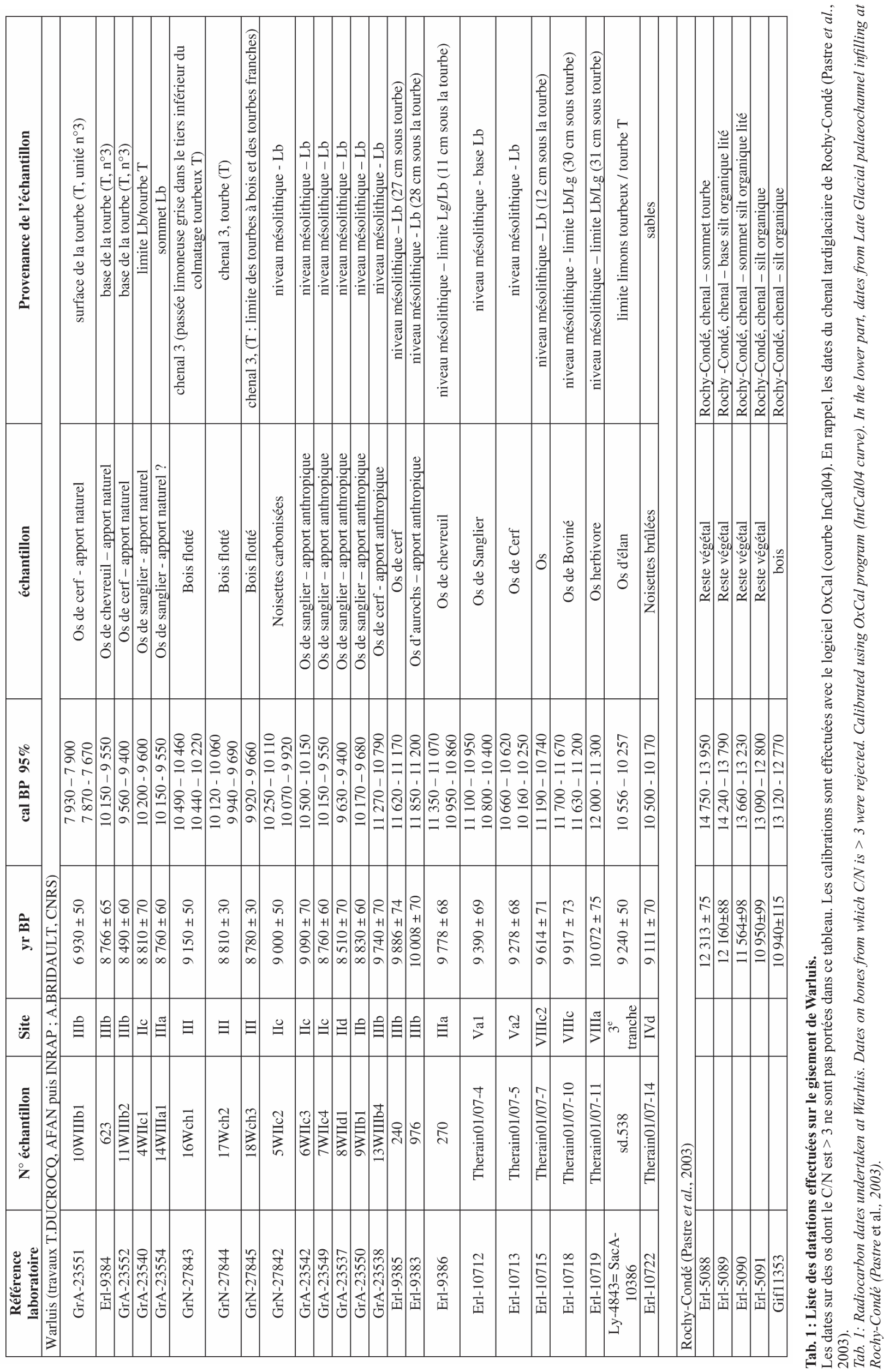




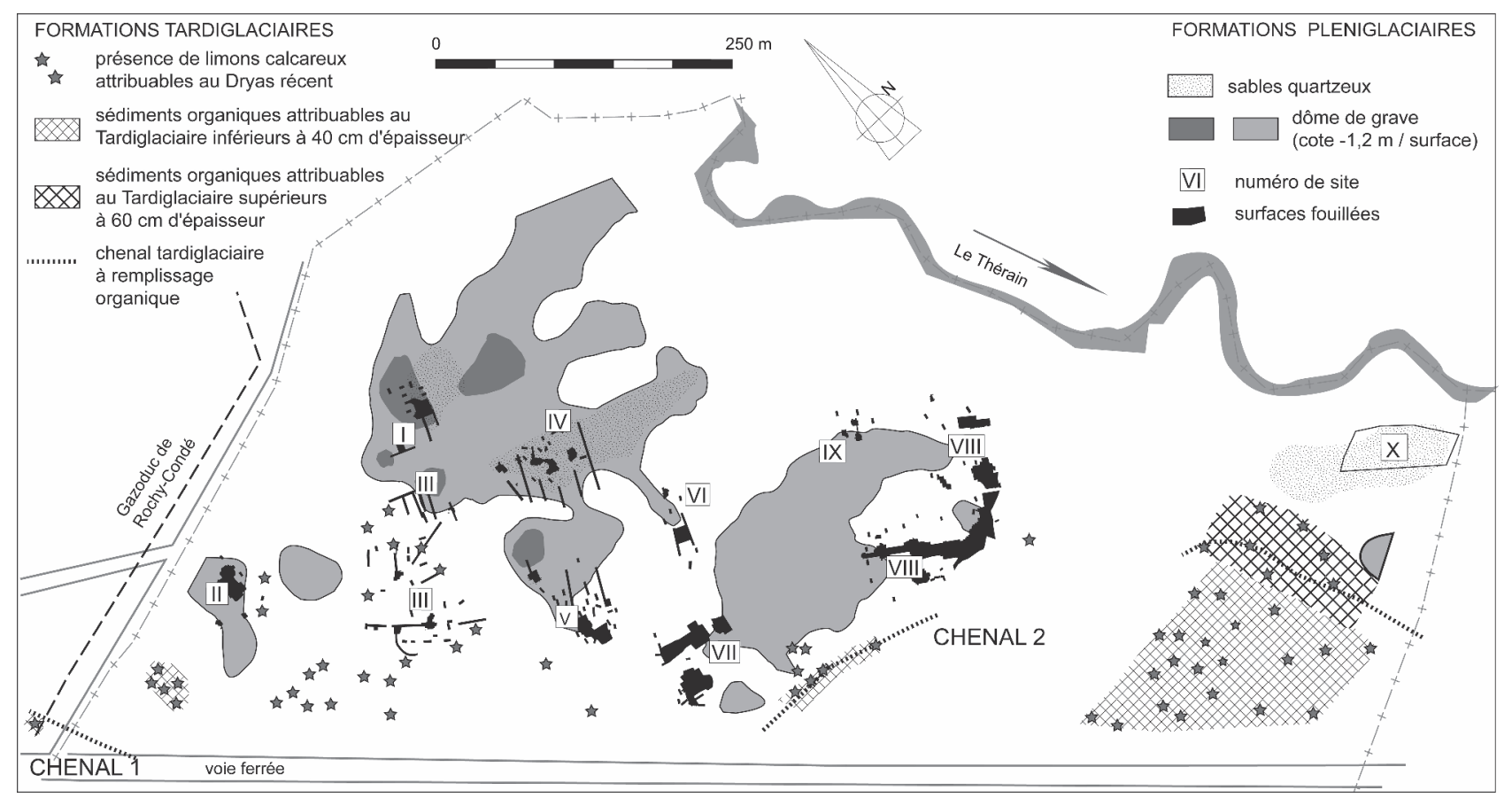

Fig. 4 : Localisation des dômes de graviers et des sédiments tardiglaciaires.

Fig. 4: Location of gravel mounds and Lateglacial sediments.

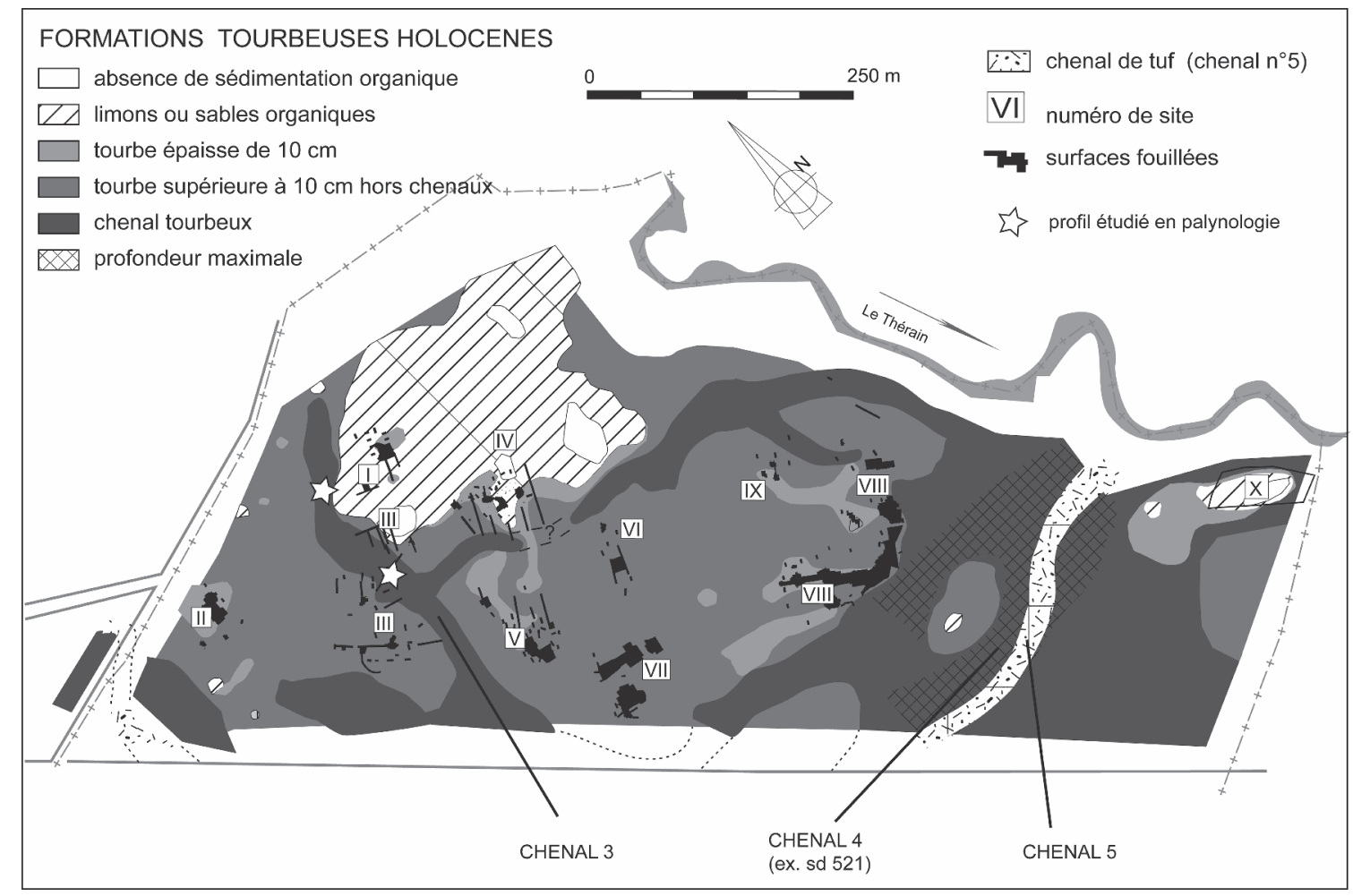

Fig. 5: Répartition des formations tourbeuses holocènes.

Fig. 5: Distribution of Holocene peaty deposits.

vers 1,20 de profondeur. La partie supérieure des tourbes déborde à l'extérieur du chenal. Le chenal alors inactif est ensuite recouvert par 20 à $40 \mathrm{~cm}$ de limons très argileux ( $\left.\mathrm{Lpl}, \mathrm{n}^{\circ} 2\right)$.

Ce chenal a fait l'objet de datations radiocarbone et d'une étude palynologique qui seront exposées plus loin. Il est stérile sur le plan archéologique, hormis quelques traces charbonneuses dans les différents limons holocènes.
Par ailleurs, vu sa position, il correspond peut-être à un ancien cours du Ru de Laversines, un affluent du Thérain.

\section{- le Chenal 4}

Le chenal 4 est une vaste forme traversant la partie sud de la carrière, qui recouvre partiellement le chenal 2. L'axe de drainage semble proche du sondage 521 donné en exemple (fig. 2 et 3 ). Le colmatage tourbeux ou limono-tourbeux atteint $1,85 \mathrm{~m}$ et repose directement 


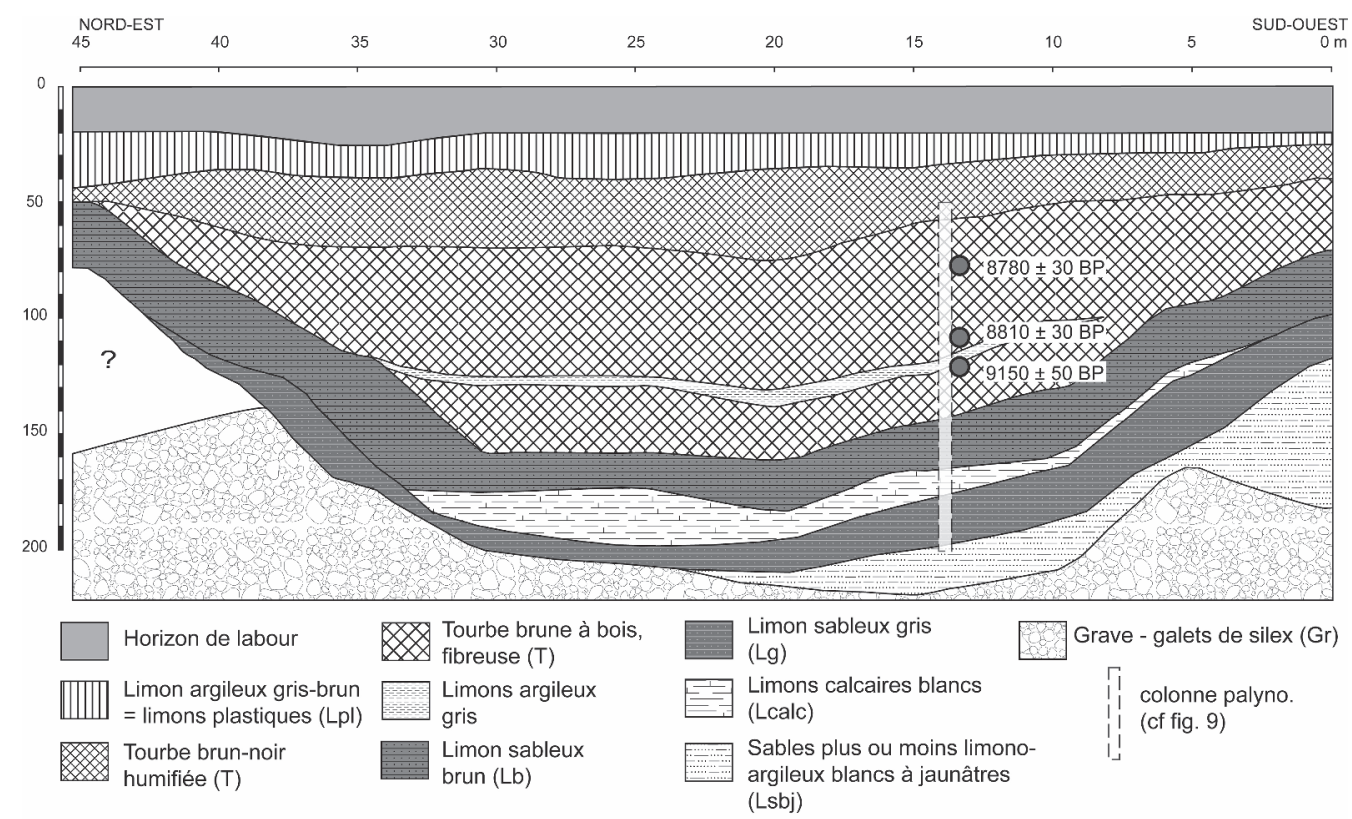

Fig. 6: Coupe du chenal 3 sur le site III.

En l'absence de cotes, la surface est considérée comme horizontale.

Fig. 6: Palaeochannel $n^{\circ} 3$ cross section on site III. The ground surface is considered as horizontal.

sur le gravier de fond. Les limons calcaires (Lcalc) sont absents. Les tourbes et limons tourbeux du chenal 4 sont probablement corrélables avec les tourbes $\left(\mathrm{T}, \mathrm{n}^{\circ} 3\right)$ postérieures aux limons calcaires (Lcalc) du chenal 3.

\section{- Le Chenal 5}

Un chenal de tuf recoupe l'ensemble des dépôts. Il est encore identifiable dans la microtopographie actuelle par un léger relief dû à une compaction différentielle entre le remplissage du chenal et les tourbes environnantes. Ce chenal est étroit, creusé jusqu'aux graviers de la nappe de fond. Le comblement du chenal est constitué de tufs meubles, dits allochtones et clastiques (Pedley, 1990; Pentecost \& Viles, 1994). La base, entre 3,2 et 3,6 m de profondeur, est caractérisée par des oncolithes géantes ( $50 \mathrm{~cm}$ de diamètre environ) formées autour de graviers de silex (5 $\mathrm{cm}$ environ). Dans le mètre inférieur sont présentes des oncolithes pluricentimétriques $(2-3 \mathrm{~cm})$. Le remplissage est ensuite composé de sable quartzeux, de sable biodétritique et de petites concrétions carbonatées, de passées limono-argileuses grises voire organiques et contient de nombreux mollusques ainsi que des bois flottés plus ou moins encroûtés. L'étude du sommet du remplissage montre un débordement sur plus de 20 à $30 \mathrm{~m}$ de large, avec intercalation dans des limons tourbeux noirs (transition T/Lpl). Au sommet se trouvent des moules d'eau douce (Unio) en position de vie. Ce débordement sur quelques dizaines de mètres a également été observé sur le site II où des lits de tuf coquillier s'intercalent dans des limons organiques hydromorphes.

\section{3 - LES ZONES HAUTES OU DÔMES}

Les zones dites «hautes» sont situées environ $50 \mathrm{~cm}$ plus haut que les zones dites «basses», ce faible écart altimétrique étant suffisant pour entraîner une évolution différente. Ces zones hautes correspondent aux dômes de graviers hérités des périodes antérieures (fig. 4). Elles sont parfois érodées.

Les tourbes franches $(T, 3)$ n'ont pas recouvert les espaces les plus hauts. Ainsi, sur le site IV, leur équivalent latéral est un limon tourbeux noir contenant une fraction importante de sable moyen (Sno, 3bis), dont l'épaisseur atteint une dizaine de centimètres.

Trois sites se placent dans cette position: les sites I, II et IV (fig. 2 et 3).

Sur le site I (fig. 2 et 3), les silex taillés mésolithiques sont quasiment au contact des graviers, sous un mince sédiment tourbeux. Ils sont pris dans un sable jaunâtre à graviers éventuellement corrélable à l'unité ${ }^{\circ} 4$.

Le site II (fig. 2 et 3 ) est également localisé sur un dôme de graviers mais la sédimentation y est plus dilatée que sur le site I, avec de haut en bas: des limons plastiques bruns $(2, \mathrm{Lpl})$, une tourbe, relativement mince dans ce secteur, de l'ordre de 10 à $20 \mathrm{~cm}(3, \mathrm{~T})$, des limons sableux organiques bruns $(4, \mathrm{Lb})$, des limons calcaires blanchâtres (5, Lcalc), des limons sableux brun-noir; il s'agit d'un équivalent latéral de $\mathrm{Lg}$, mais dans un faciès plus sombre (6), les graviers de fond $(9, \mathrm{Gr})$.

Sur le site IV, le sable noir organique (Sno, 3bis), équivalent latéral des tourbes $(T, 3)$, repose sur un sable plus ou moins bariolé jaunâtre à taches orangées s'assombrissant vers le bas pour atteindre une teinte nettement gris-brun. Ce sable brun repose sur un sable limoneux blanc (Lsbj, 8) emballant des concrétions ferrugineuses orangées (hydromorphie). En dessous apparaissent les graviers roulés de la nappe de fond (Gr, 9). La limite entre les sables bruns et les sables limoneux blanchâtres est marbrée (bioturbation?). Lors de la fouille, d'assez nombreux petits graviers de silex $(2-3 \mathrm{~cm})$ ont été observés dans les sables jaunes et bruns, qui contiennent 
également l'industrie mésolithique. Celle-ci a été repérée sur environ $25 \mathrm{~cm}$ d'épaisseur.

\section{4 - LES ZONES BASSES}

Les zones basses correspondent principalement aux sites III, V, VI, VII, VIII et IX (fig. 2 et 3).

La base de la séquence pédo-sédimentaire est constituée des graviers de fond (Gr, 9), généralement recouverts de sable quartzeux ( $\mathrm{Sq}$, 9bis) et de sables limoneux blanchâtres $(\mathrm{Lsbj}, 8)$ pouvant atteindre $50 \mathrm{~cm}$ d'épaisseur. La transition vers les limons gris (Lg, 6) sus-jacents est perturbée, avec des teintes jaunâtres et des concrétions traduisant des phénomènes d'oxydo-réduction. L'industrie du Paléolithique final à Federmesser est présente au-dessus de la limite Lsbj/Lg. Sur les limons gris ( Lg, 6) reposent les limons bruns $(\mathrm{Lb}, 4)$ : la limite est généralement très diffuse.

Les limons sableux organiques ( $\mathrm{Lg}, 6 \mathrm{et} \mathrm{Lb}, 4)$ forment l'essentiel des dépôts à intérêt archéologique de la carrière. Leurs caractéristiques seront exposées plus loin. Dans les zones basses, les tourbes $(T, 3)$ sont présentes partout au-dessus des limons sableux bruns (Lb, 4).

\section{3 - QUELQUES ÉLÉMENTS SUR LES OCCUPATIONS MÉSOLITHIQUES ET PALÉOLITHIQUES}

Le Paléolithique supérieur est présent dans les zones basses sur les sites VI, VII, VIII et IX (fig. 2). Des amas de déchets de débitage lithique et des foyers sont bien en place dans la partie inférieure des limons organiques et plus précisément dans les premiers centimètres du Lg sur les sites VII et VIII. En revanche, de nombreux artefacts ont subi des déplacements post-dépositionnels et se trouvent dans le Lb et parfois au contact des tourbes sus-jacentes. La majeure partie des industries montre l'extraction de lames irrégulières peu calibrées à large talon lisse (percussion rentrante). Outre des grattoirs et des burins, l'outillage comporte souvent de nombreux éléments de projectiles (essentiellement des monopointes à dos; fig. 7 ligne du bas). Ces industries sont comparables à des séries décrites dans la Somme par Fagnart (1997) qui les attribue au Paléolithique final à Federmesser de l'Allerød. Elles sont souvent assimilées à l'Azilien (Valentin et al., 2004)

Une seconde phase d'occupation est clairement datée du début de la chronozone du Préboréal sur les zones basses. Elle est surtout matérialisée par de la faune associée à quelques vestiges lithiques grossièrement situés à l'interface $\mathrm{Lg} / \mathrm{Lb}$ sur les sites III et VIIIa. L'industrie n'est pas encore bien caractérisée en raison de perturbations qui peuvent être responsables de l'intrusion d'armatures issues des niveaux sus-jacents.

La partie supérieure du limon organique des zones basses $(\mathrm{Lb})$ révèle des concentrations plus ou moins denses de vestiges lithiques et osseux dispersés sur une quinzaine de centimètres d'épaisseur. Une première approche typologique (Ducrocq et al., 2008) révèle le caractère pluriel de ce Mésolithique ancien, avec des industries à affinités nordiques caractérisées par un spectre microlithique restreint aux seules pointes à base non retouchée (site $\mathrm{V}$; fig. 7 ligne du milieu), et des ensembles plus diversifiés à pointes à base non retouchée, pointes à base retouchée et triangles.

Les zones hautes comportent des concentrations de vestiges lithiques et osseux bien circonscrites sur quelques dizaines de mètres carrés (sites I, II et IV). Les restes de sangliers et les coquilles carbonisées de noisettes sont toujours présents. Les spectres microlithiques sont dominés par les segments et les pointes à base retouchée (fig. 7 ligne du haut). Des assemblages comparables sont bien datés entre 9100 et 8700 BP dans le bassin de la Somme (Ducrocq, 2001; Fagnart et $a l .$, 2008). Un ensemble à triangles et pointes à base retouchée témoigne du dernier passage des chasseurscueilleurs sur le site.

Les surfaces d'occupations préhistoriques évidentes sont rares. Des foyers et des amas de débitage paléolithiques en matérialisent une au sein du $\mathrm{Lg}$ sur les sites VII et VIII. L'interface $\mathrm{Lb} / \mathrm{Lg}$ correspond parfois à des concentrations denses en vestiges lithiques et osseux toujours datées de la transition tardiglaciaire-holocène. La perception de telles surfaces est plus délicate pour le Mésolithique du Lb. Au début des fouilles, deux hypothèses étaient envisagées pour expliquer une forte dispersion verticale: soit une sensible bioturbation de niveaux quasiment en place, soit un remaniement total des vestiges apportés avec les sédiments. Le très bon état physique des artefacts, l'organisation spatiale des vestiges sous forme de concentration cohérente avec des secteurs bien individualisés (zone à pièces chauffées, à microlithes, à déchets de débitage...) et la réalisation de nombreux remontages orientent naturellement vers la première solution.

Il est encore prématuré d'aborder les aspects palethnologiques. Cependant, la plupart des occupations révèlent des aires de combustion plus ou moins discernables avec des témoignages de débitage lithique, d'activités domestiques et de façonnage d'éléments de projectiles. Les outils du fonds commun sont abondants dans le Paléolithique final et le Mésolithique à affinités septentrionales. Ils sont plus rares sur les autres concentrations mésolithiques. Quelques petites concentrations révèlent des spectres d'activités restreints. Le Mésolithique initial reste pour l'instant énigmatique. L'abondance de la faune pourrait témoigner d'activités spécifiquement liées au traitement de carcasses.

\section{4 - CARACTÉRISTIQUES DES SÉDIMENTS CONTENANT LES VESTIGES DANS LES ZONES BASSES}

\section{1 - DEUX UNITÉS DISTINCTES}

Les limons sableux organo-minéraux contenant les industries lithiques se séparent en deux parties d'inégale épaisseur, caractérisées par une couleur différente : 

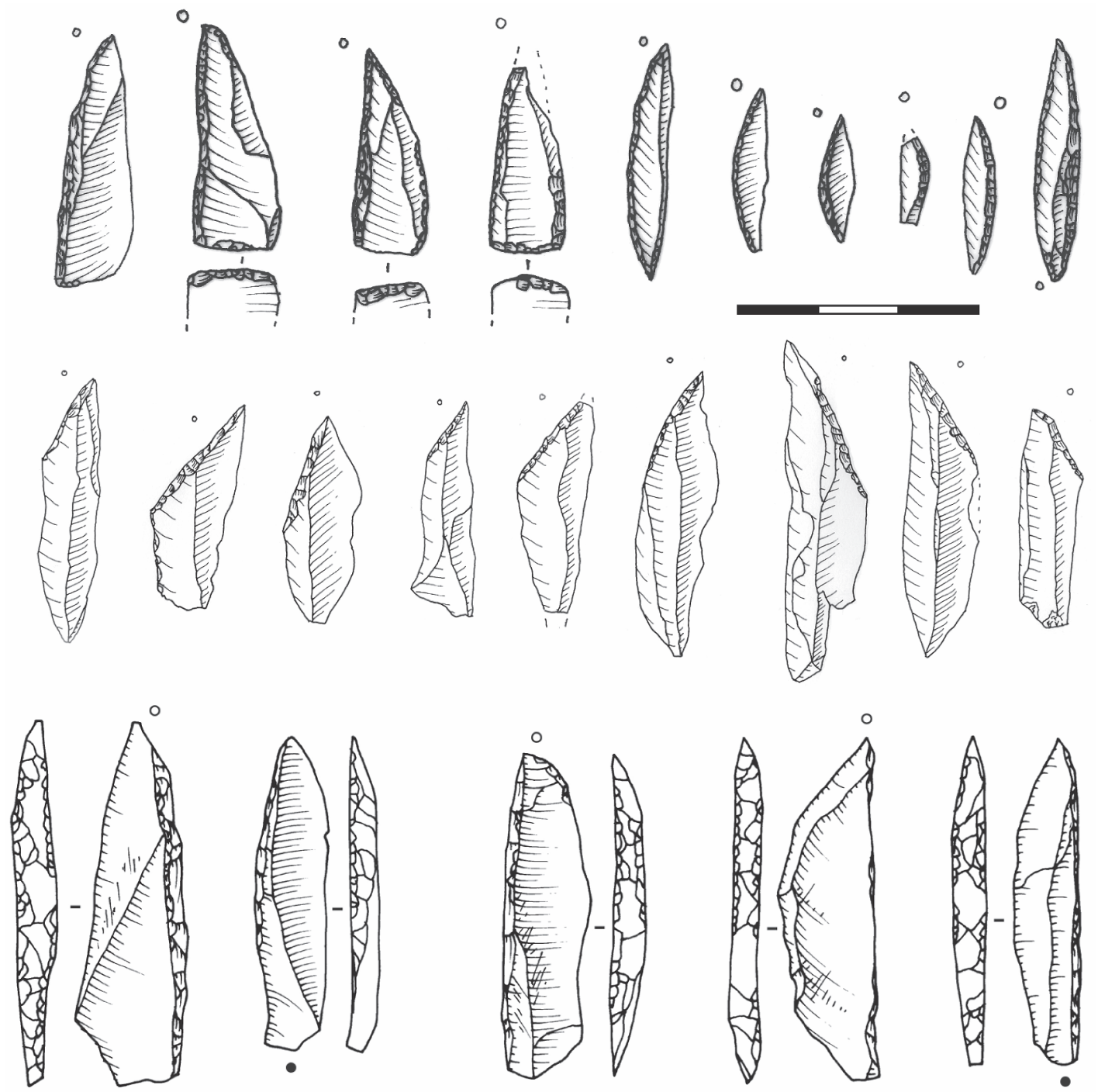

Fig. 7 : «Armatures» du Paléolithique final du site VIIa3 (ligne du bas, dessins de L. Juhel), du Mésolithique ancien à affinités nordiques du site Va2 (ligne intermédiaire, dessins T. Ducrocq) et du Mésolithique du début de la Chronozone du Boréal du site I (ligne du haut, dessins T. Ducrocq).

Fig. 7: "Armatures» from the Latest Palaeolithic, site VIIa3 (bottom, drawings by L. Juhel), from the Early Mesolithic with Nordic similarities, site Va2 (middle, drawings by T. Ducrocq) and from the Mesolithic of the beginning of the Boreal chronozone, site I (top, drawings by T. Ducrocq).

les limons bruns ( $\mathrm{Lb}$, unité $\left.\mathrm{n}^{\circ} 4\right)$ et les limons gris $(\mathrm{Lg}$, unité $\mathrm{n}^{\circ}$ 6). Ainsi, sur le site VIa, Lb atteint $20 \mathrm{~cm}$, $\mathrm{Lg}$ environ $15 \mathrm{~cm}$. La limite est généralement progressive et diffuse, parfois difficilement perceptible. Cette différenciation s'est avérée cruciale lors de la fouille puisque l'essentiel des vestiges mésolithiques se situe dans le limon brun Lb, tandis que le limon gris Lg a principalement fourni des vestiges du Paléolithique final à Federmesser. Cette tendance a des implications qui seront discutées plus loin, en relation avec les études malacologiques.

Notons que pour le Paléolithique, la faune n'est pas conservée alors que les sédiments sont carbonatés, ce qui, avec la patine bleue des silex, pourrait être expliqué par une exposition plus longue aux agents météoriques.

$\mathrm{Lb}$ et $\mathrm{Lg}$ sont des limons sableux ou des sables limoneux. Sur le site VIIIa, au niveau de la colonne de prélèvements malacologiques BK53, la teneur en sable de Lb est entre 58 et $63 \%$ et atteint même $75 \%$ dans l'échantillon immédiatement sous-jacent à la tourbe. Sur le VIIIcd, en DO83, le sédiment est nettement plus limoneux (33 à $41 \%$ de sable). La fraction sableuse est constituée de sables moyens à grossiers. Ce sont des sédiments à matrice carbonatée, ce qui a permis la conservation de la faune, en tout cas pour les niveaux mésolithiques. Seuls les centimètres supérieurs de Lb sont décarbonatés, sans doute sous l'action de la matière organique issue de la tourbe $\left(\mathrm{T}, \mathrm{n}^{\circ} 3\right)$.

Les figures sédimentaires sont rares au sein de ces dépôts. Des lits de sable propre ruisselé ont été observés ponctuellement sur le site VIIIa.

\section{2 - OBSERVATIONS MICROMORPHOLOGIQUES}

Quelques lames minces sont issues des sites VIII et IX (fig. 8 et tab. 2).

De manière générale, les observations micromorphologiques (tab. 2) ne montrent pas de différence majeure 
entre $\mathrm{Lg}$ et $\mathrm{Lb}$. La différence de couleur tiendrait au fait que Lg est plus carbonaté.

La faible différenciation pédologique observable en lame mince s'accorde bien avec les aspects macroscopiques: le sédiment apparaît largement homogène. La faible évolution des sols est courante en milieu alluvial, d'autant que le développement du sol a été interrompu par la mise en place des tourbes. Elle est d'autant plus ténue que la teneur en sable limite l'agrégation. Les témoins d'activité des vers de terre (quelques logettes, sphérules de calcite) sont moins marqués que l'activité des acariens. Il s'agit d'oribates, qui vivent souvent dans la litière et l'humus (Siira-Pietikäinen et al., 2008). Il semble également s'agir d'une activité ancienne. Cette prédominance des acariens peut s'expliquer par la teneur en sable du sédiment et la présence régulière de la nappe phréatique qui défavorisent les lombrics (Bullinger-Weber et al., 2007).
L'essentiel des traits observés résulte d'une bioturbation importante qui masque les distinctions entre les deux unités et toute structuration originelle du dépôt. Il s'agit principalement d'une bioturbation due aux racines.

Seuls restent présents des litages «fantômes», c'està-dire des alignements discontinus de grains de quartz, interprétés comme les restes d'un litage fortement bioturbé. Ces restes de litage traduisent une accrétion sédimentaire par apports fluviatiles.

Sur le site VIII, dans le carré BK 58 (lame 6, fig. 8), un niveau d'industrie bien marqué avec plusieurs pièces à plat a été mis au jour. En lame mince, cette surface d'occupation est juste marquée par la présence de quelques esquilles et charbons: aucun hiatus sédimentaire n'apparaît. Seule la présence de l'industrie témoigne d'un arrêt dans la sédimentation.

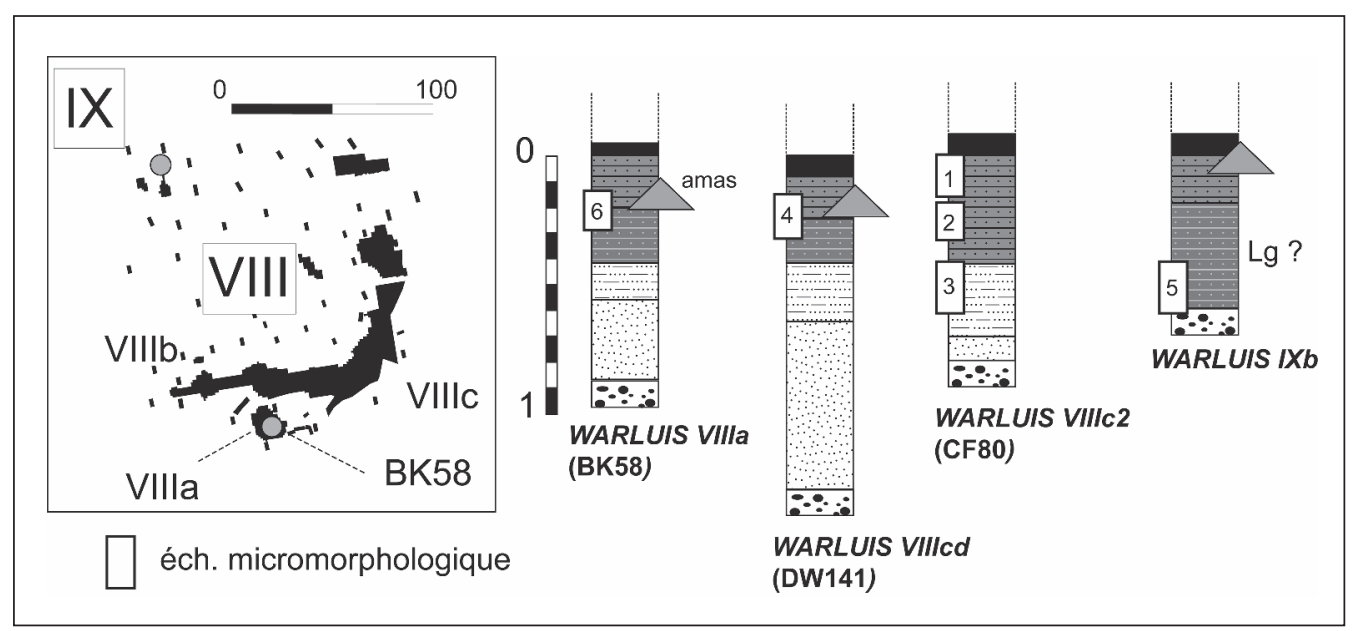

Fig. 8: Position des échantillons micromorphologiques (sites VIII et IX).

Fig. 8: Micromorphological samples location on stratigraphic profiles (sites VIII and IX).

\begin{tabular}{|c|c|}
\hline fraction grossière & $\begin{array}{l}\text { sédiment sableux, sable moyen à grossier mal classé }(200 \mathrm{à} 800 \mu \mathrm{m}) \text {, limons loessiques plus ou moins abondants (quartz environ } 50 \mu \mathrm{m} \text {, } \\
\text { parfois paillettes de micas), grains de silex fréquents, quelques graviers nombreux bioclastes, gastéropodes entiers, fragment de calcite, } \\
\text { sphérules (= biosphérö̈des, résultant de l'action des lombricidés) }\end{array}$ \\
\hline masse basale & matrice poussiéreuse très carbonatée sauf au sommet de Lb (probable destruction favorisée par la MO) \\
\hline traits carbonatés & hyporevêtements carbonatés autour de chenaux racinaires dans certaines lames surtout à la base de $\mathrm{Lg}$ \\
\hline agrégation & pas d'agrégation (pédogenèse peu marquée) \\
\hline porosité & $\begin{array}{l}\text { porosité de chenaux et quelques fentes (dues à la disparition d'éléments végétaux ?). Pas de porosité intergranulaire malgré une granulométrie } \\
\text { sableuse : tout est colmaté par la matrice silto-carbonatée }\end{array}$ \\
\hline $\begin{array}{l}\text { traits } \\
\text { d'hydromorphie }\end{array}$ & à la base de Lg et dans Lsbj, légère hydromorphie (lame 3) \\
\hline activité biologique & $\begin{array}{l}\text { - nombreuses racines avec tissus végétaux fortement dégradés et attaqués par les oribates, acariens du sol dont on retrouve d'abondantes } \\
\text { déjections (petits pellets noirs ellipsoïdes ou arrondis) } \\
\text { - éléments végétaux à plat dégradés (racines ou feuilles) } \\
\text { - logettes de diapause de vers de terre comblées par un sédiment identique à l'encaissant }\end{array}$ \\
\hline $\begin{array}{l}\text { structures } \\
\text { sédimentaires }\end{array}$ & dans l'ensemble des lames, alignements discontinus de grains de quartz, interprétés comme les restes d'un litage fortement bioturbé \\
\hline
\end{tabular}

Tab. 2: Traits pédo-sédimentaires des sédiments $\mathbf{L g}$ et $\mathbf{L b}$.

Tab. 2: Pedo-sedimentary features of $L g$ and $L b$. 


\section{3 - CONCLUSION}

Les rares traits sédimentaires observés plaident en faveur d'une origine fluviatile pour Lb et Lg. La bioturbation très importante due principalement aux racines a homogénéisé le profil. La limite entre les deux unités est diffuse et l'analyse en lame mince ne permet pas de mettre en évidence un éventuel hiatus sédimentaire. Cependant, l'existence d'un tel hiatus est nécessaire pour expliquer la répartition des industries lithiques; il est avéré d'après l'évolution des cortèges malacologiques.

\section{5 - ÉTUDE DES BIOINDICATEURS}

\section{1 - LA VÉGÉTATION}

L'étude palynologique de Warluis concerne deux petits carottages, implantés dans le chenal 3 (fig. 6), respectivement dans le site III et à l'extrémité de la tranchée 30 de Warluis I (fig. 2). Pour l'heure, l'analyse a privilégié les dépôts contemporains des occupations mésolithiques: seuls 22 prélèvements ont été étudiés avec un maillage trop lâche des niveaux adjacents. Létude repose sur le décompte de 8481 pollens et spores avec une moyenne de 362 grains comptés et de 21 taxons individualisés par échantillon, seuils estimés représentatifs en contexte organique et humide (Reille, 1990). La conservation du matériel sporo-pollinique est médiocre. Elle est à l'origine des taux élevés de pollens indéterminables mais n'entraîne pas la prédominance des types polliniques résistants (Cichorioidées, Polypodium), privilégiés lors de la destruction des grains les plus fragiles (Havinga, 1984). Du fait de la pénétration des niveaux par des racines d'hygrophytes, une extrême vigilance a été portée à la reconnaissance de contaminations. Si de tels phénomènes n'ont pas été mis en évidence, des états de conservation variables ont parfois été observés sur un même taxon. Ces problèmes de corrosion et de possibles contaminations mènent donc à exprimer quelques réserves quant à la représentativité des données polliniques de Warluis; l'évolution perçue au sein des cortèges nous incline toutefois à proposer des interprétations, tant biostratigraphiques que paléoécologiques. L'importance de la végétation locale nous a incitées à construire divers diagrammes polliniques dont sont exclus les taxons hygrophiles qui peuvent masquer l'évolution de la végétation régionale. Néanmoins, le diagramme présenté (fig. 9) a été établi sur une somme de base dont seuls sont exclus Sphagnum, les fougères, et les indéterminables. Cinq zones polliniques locales, elles-mêmes subdivisées, ont été individualisées (fig. 9 et tab. 3).

War $a=$ zone à herbacées (Warluis III = 199 à $157 \mathrm{~cm}$ )

Le paysage très ouvert est dominé par une strate herbacée à caractère steppique. Les rares ligneux présents (bouleaux, genévriers, saules, pins) sont des essences héliophiles. L'organisation des cortèges est caractéristique du Tardiglaciaire mais le pas d'échantillonnage est trop large pour suivre l'évolution détaillée de la végé-

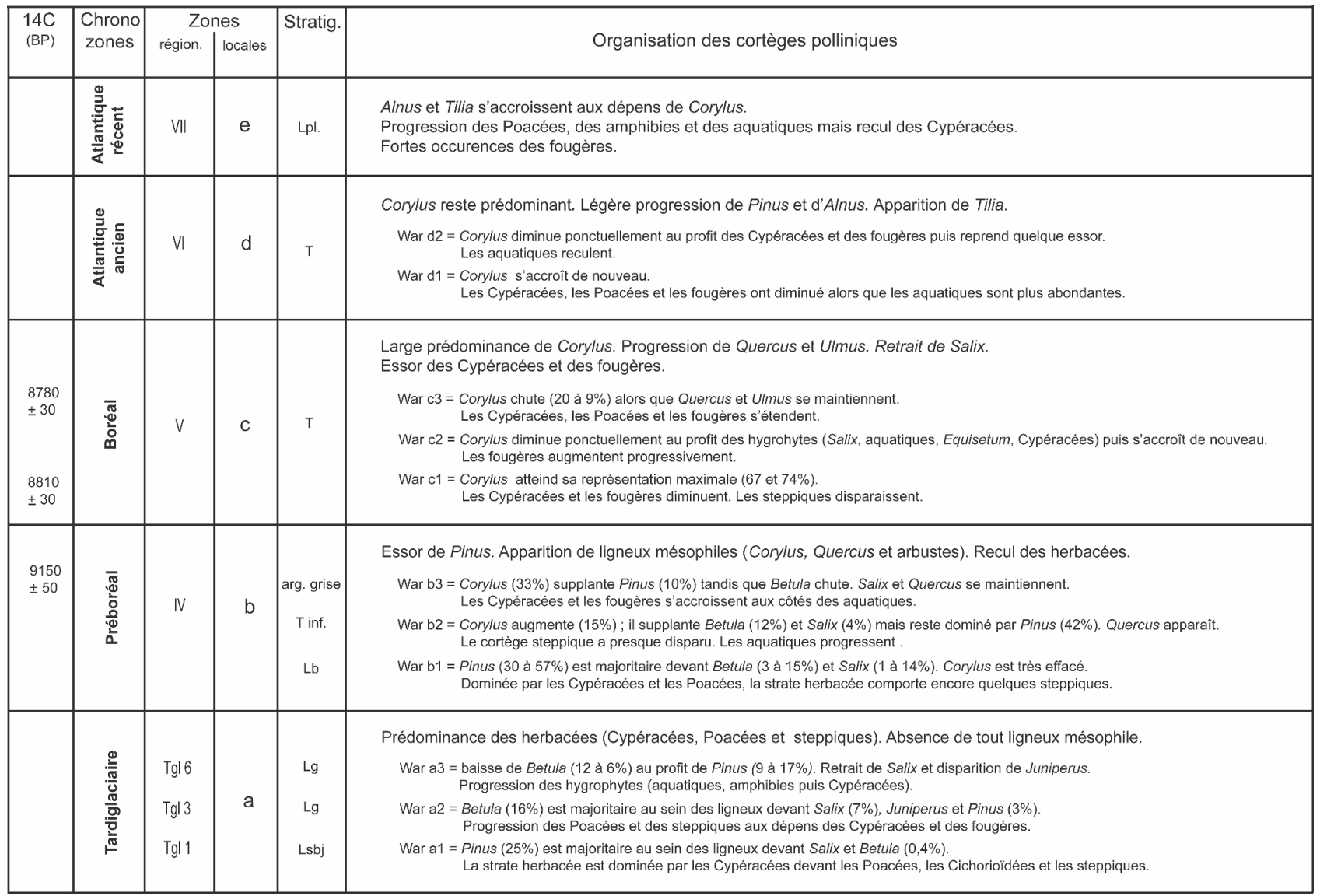

Tab. 3 : Description des zones polliniques locales de Warluis et corrélation aux zones régionales du Bassin parisien.

Tab. 3: Description of the local pollen assemblage zones from Warluis and correlations with regional pollen assemblage zones of the Paris basin. 


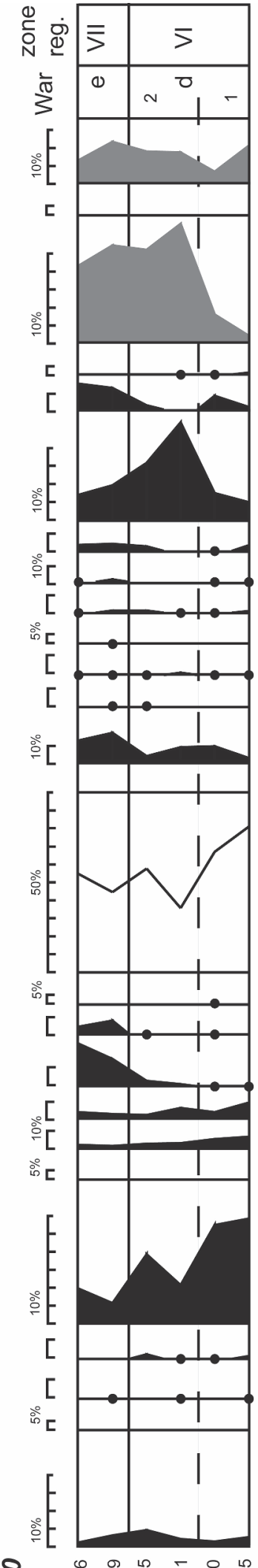

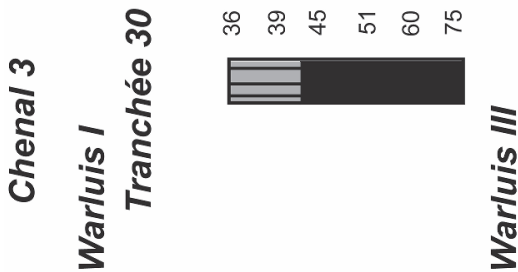

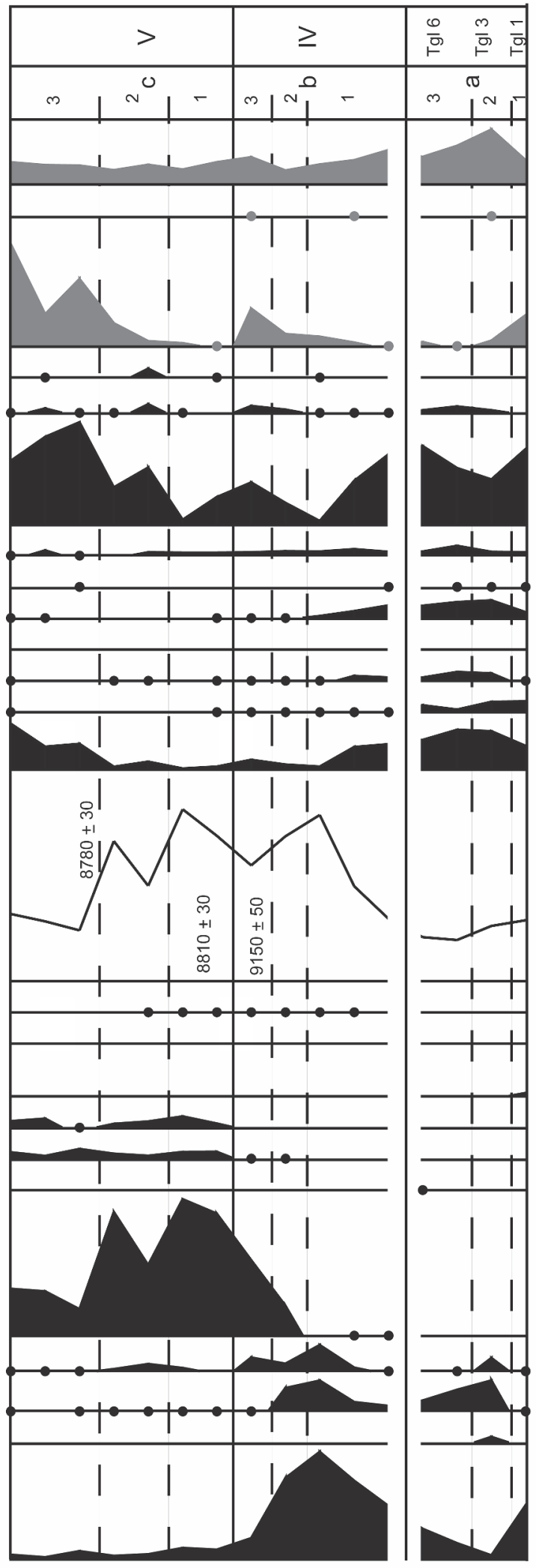

"4/"

s//2/,

sanglng

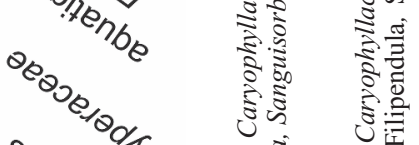

$\left.2 / \frac{\pi}{2}\right)$

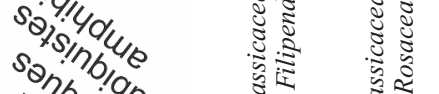

$8 \%$ के है के

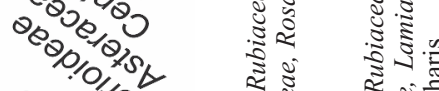

${ }^{{ }^{2}{ }^{\circ} / \%} / \%$ \%

วิ

4

So, की

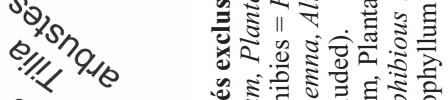

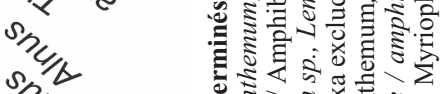

s/2

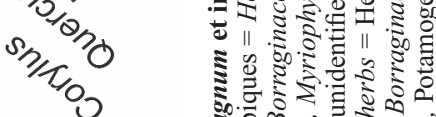

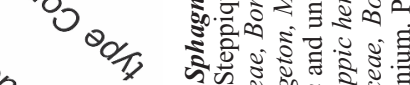

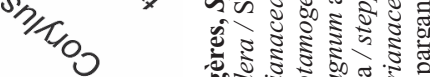

t/8

\&

\%/ $1 / 2 \%$

"/n

"थ, काँ है

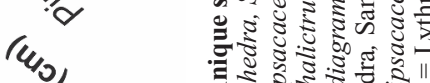

\%),

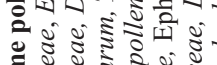
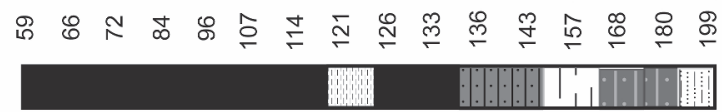
tation et se référer précisément à la dynamique régionale (Leroyer \& Allenet, 2002). En War a1, les ligneux semblent presque totalement absents de l'environnement car les occurrences notables du pin relèvent plutôt de sa forte dissémination pollinique en milieu ouvert que de son implantation locale (Heim, 1970; Barthélémy, 1985). Les versants accueillent une steppe claire et le fond de vallée abrite une prairie humide à Poaceae, Cyperaceae et amphibies. Ces assemblages sont caractéristiques de la zone régionale Tgl 1 (Ponel et al., 2005), qui évoque le Dryas ancien d'un point de vue palynologique (LimondinLozouet et al., 2002). En War a2 (base Lg), des arbustes pionniers (genévriers, bouleaux et saules) sont présents tandis que la steppe s'est étendue sur les versants. Quelques aquatiques signalent l'existence d'une lame d'eau peu profonde dans le chenal. Ce niveau peut être corrélé avec la zone régionale $\mathrm{Tgl} 3$ (fin du Bølling) ou éventuellement Tgl 5 (début de l'Allerød). En War a3 (Lg), des boisements clairs à bouleaux et pins se sont développés. Dans le chenal, la diminution progressive de la lame d'eau induit la mise en place d'un bas marais à Cyperaceae au détriment des herbacées amphibies et aquatiques. Ces assemblages sont caractéristiques du début de la zone régionale $\operatorname{Tgl} 6$ ( $2^{\mathrm{e}}$ partie de l'Allerød) lors $\mathrm{du}$ croisement des courbes du bouleau et du pin (Leroyer \& Allenet, 2002).

War $b=$ zone à pin, bouleau et noisetier (Warluis III = $143 \grave{a} 121 \mathrm{~cm}$ )

Une pinède est installée aux alentours de Warluis. Dans un premier temps (War b1, Lb), des boisements clairs à bouleaux et saules perdurent alors que les noisetiers commencent à disséminer. Le milieu reste assez ouvert pour permettre le maintien d'herbacées héliophiles à connotation steppique. Ensuite (War b2 et 3, tourbe et argile grise), les noisetiers se développent aux dépens des bouleaux et des pins. La raréfaction des herbacées héliophiles indique que les boisements deviennent plus denses. Une petite saulaie reste implantée en fond de vallée tandis que le chenal est colonisé par une végétation aquatique. La large prédominance du pin permet d'attribuer la deuxième zone au Préboréal avec une partition en deux phases (pin et bouleau puis pin et noisetier), caractéristique de cette période dans le Bassin parisien (Leroyer, 1997). Cette attribution est corroborée par la date de $9150 \pm 50 \mathrm{BP}(\mathrm{GrN}-27843)$, obtenue à $121 \mathrm{~cm}$.

War $c=$ zone à noisetier, chêne et orme (Warluis III = 114 à $59 \mathrm{~cm}$ )

Le paysage est dominé par une corylaie où se développent quelques chênes, ormes et arbustes. Des variations édaphiques entraînent des modifications des cortèges. Ainsi, la végétation hygrophile, absente en War $\mathrm{c} 1$ (tourbe), colonise à nouveau le chenal en War $\mathrm{c} 2$ (tourbe). Le retrait du noisetier à $96 \mathrm{~cm}$ a été vérifié par l'exclusion des hygrophytes des sommes de base: il est, pour partie, lié au développement ponctuel du saule. En War c3 (tourbe), le fond de vallée est occupé par un bas marais qui masque la perception des boisements. La prédominance du noisetier et la bonne représentation de l'orme permettent de rattacher la troisième zone au Boréal (Leroyer, 2006a). Les variations du noisetier relè- vent des modifications édaphiques particulièrement bien enregistrées dans cette séquence où la végétation locale joue un rôle majeur.

War $d=$ zone à noisetier, chêne, orme et tilleul (Warluis I $=75 \grave{a} 45 \mathrm{~cm}$ )

A l'exception de l'apparition du tilleul au sein de la chênaie, le paysage végétal change peu en zone War d (tourbe). L'abondance du noisetier relève vraisemblablement de sa participation aux boisements de versant comme à ceux du fond de vallée où une aulnaie commence à s'implanter. Les deux sous-zones illustrent là encore des variations édaphiques. En War d1, le chenal semble à nouveau en eau au regard de la reprise des aquatiques et de quelques amphibies. En War d2, le colmatage du lit permet le développement d'hélophytes (Cyperaceae et fougères). La quatrième zone est rattachée à l'Atlantique ancien, caractérisée dans le Bassin parisien par l'apparition du tilleul et une légère reprise du pin (Leroyer, 2004). L'importance du noisetier dans ces niveaux peut être imputée à un effet local.

War e = zone à aulne et tilleul (Warluis $I=39$ et $36 \mathrm{~cm}$ )

L'aulnaie progresse en fond de vallée aux dépens des noisetiers. Sur les versants, la chênaie évolue vers un faciès à tilleuls mais les noisetiers et ormes participent toujours à la formation. L'essor de l'aulne et du tilleul permettent de rattacher la zone War e à l'Atlantique récent selon la dynamique de végétation établie dans le Bassin parisien (Leroyer, 2006b).

Malgré la mauvaise conservation des stocks polliniques, l'analyse de Warluis permet de documenter l'environnement des groupes mésolithiques occupant les lieux. Bien que l'importance de la végétation locale masque pour partie les apports régionaux, la dynamique de végétation est caractéristique des successions végétales reconnues dans le Bassin parisien durant le Tardiglaciaire et le début de l'Holocène.

\section{2 - LES MALACOFAUNES}

Le site de Warluis a fait l'objet d'un échantillonnage malacologique multiple, réparti sur huit profils recoupant les différents faciès sédimentaires. La multiplication des colonnes de prélèvements permet de contrôler l'identification des paramètres environnementaux pertinents au niveau du site par rapport à des signaux plus ponctuels qui pourraient être liés à des conditions très localisées. Par ailleurs, cette multiplicité est associée à la résolution de questionnements archéologiques précis. Dans cet article sont présentés les premiers résultats issus de trois profils concernant des sites de la zone basse, IIIb, VIIIa et VIIIc (fig. 2, 3, 10 et 11). Ils permettent de poser les bases d'une reconstitution paléoenvironnementale du site à partir de l'évolution des malacocénoses en y insérant les différentes occupations humaines.

La stratigraphie des profils étudiés se décompose en trois unités (fig. 3). A la base, un niveau de sables limoneux gris clair à blanchâtres (Lsbj, $\left.\mathrm{n}^{\circ} 8\right)$ est présent sur les profils IIIb et VIIIc. Sur le site VIII ce premier dépôt est surmonté par un limon sableux gris $\left(\mathrm{Lg}, \mathrm{n}^{\circ}{ }^{6}\right)$ qui 


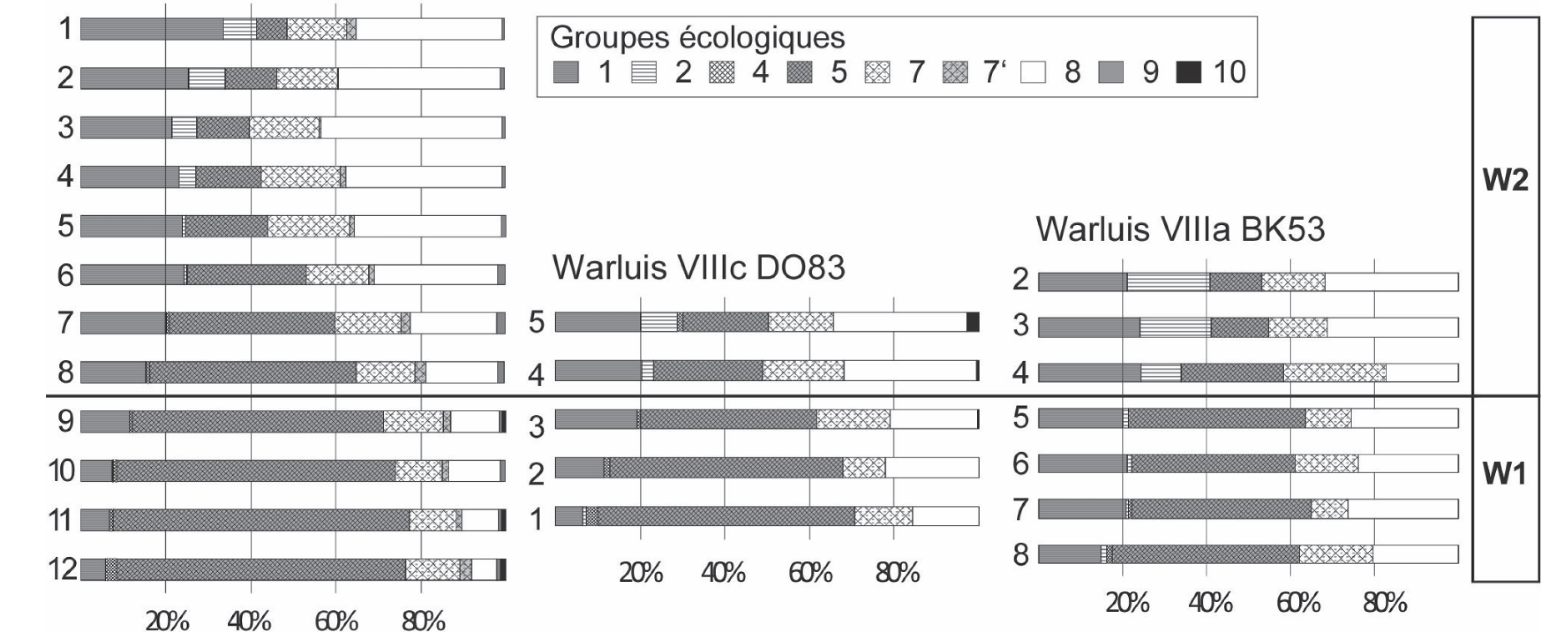

Fig. 10 : Spectres malacologiques des profils de Warluis.

Les espèces ont été réparties au sein des groupes écologiques définis par Puisségur (1976). La proportion de ces derniers est calculée en pourcentages par rapport à l'effectif total de chaque échantillon pour illustrer les variations des composantes majeures de l'environnement. Groupes: 1- Forestier, 2- Semi-forestier, 4- Steppique, 5- Terrain découvert, 7- Mésophile, 7’- Limaces, 8- Hygrophile, 9- Palustre, 10- Aquatique.

Fig. 10: Malacological spectra from Warluis profiles. Species are distributed within ecological groups after Puisségur (1976). Percentages of these groups are calculated versus total amount of shells and illustrate the variations of main environmental components. Ecological groups: 1- Forest, 2-Semi-forest, 4-Steppic, 5- Open ground, 7-Mesophilous, 7'- Slugs, 8- Hygrophilous, 9- Marsh, 10- Aquatic.

contient en VIIIc une industrie du Paléolithique final de type Federmesser. Sur le profil VIIIa des pierres de foyer sans industrie ont été retrouvées au sommet du limon gris. En revanche, ce niveau (Lg) n'a pas été formellement identifié sur le profil IIIlb. Le niveau supérieur est un dépôt limoneux brun $\left(\mathrm{Lb}, \mathrm{n}^{\circ} 4\right)$. Cette unité qui contient les occupations du Mésolithique est représentée sur les trois profils étudiés. Elle est surmontée par une tourbe ( $\mathrm{T}$, $n^{\circ} 3$ ) stérile en restes coquilliers.

\section{Zonation malacologique}

Les profils ont été échantillonnés en continu selon un pas de 5 à $10 \mathrm{~cm}$ afin d'obtenir des reconstitutions environnementales à haute résolution. Globalement les dépôts de Warluis sont riches en coquilles (tab. 4). La teneur fossilifère des sédiments est bonne dans le niveau sablo-limoneux de base puis elle augmente sensiblement pour atteindre des maxima dans les limons bruns Lb. $\mathrm{Au}$ sommet de cette unité, les effectifs déclinent. Cette évolution est directement liée à la proximité de la tourbe sus-jacente qui favorise la décarbonatation de la partie supérieure des limons et affecte la conservation des coquilles. Ceci est particulièrement sensible sur le profil VIIIa où les deux derniers prélèvements apparaissent très appauvris. La liste globale de faune (tab. 4) totalise 41 taxons dont 5 seulement sont des espèces aquatiques. Ces dernières sont représentées de manière très ponctuelle dans les assemblages, elles témoignent d'un cours d'eau proche mais dont l'influence reste discrète au niveau des points étudiés.

La distribution des effectifs au sein des groupes écologiques (fig. 10) permet d'identifier trois ensembles principaux dans les assemblages malacologiques de Warluis: les mollusques de milieu forestier (groupes 1 et 2), les espèces d'habitat ouvert (groupes
4 à 7) et les taxons de zone humide (groupes 8 à 10). La variation de ces trois composantes amène à distinguer deux zones qui sont nommées $\mathrm{W}$ pour Warluis et numérotées de la base vers le sommet. Les mollusques de milieu ouvert dominent les spectres des échantillons de la première zone ( $\mathrm{Lsbj}$ et $\mathrm{Lg}$ ). Dans les assemblages de la zone W2 (Lb), ce sont les taxons de biotopes fermés et de milieu humide qui constituent le groupe le plus important. La transition apparaît bien tranchée sur les profils du site VIII alors que les spectres de Warluis IIIb présentent un passage de $\mathrm{W} 1$ à $\mathrm{W} 2$ beaucoup plus graduel qui s'étend sur deux à trois échantillons (de 9 à 7 , fig. 10). Le choix du positionnement de la limite entre les échantillons 9 et 8 sur ce profil s'appuie sur une forte augmentation de la diversité spécifique et des effectifs entre les deux prélèvements (tab. 4). Ces variations mettent en évidence une évolution du paysage vers une fermeture du couvert végétal de la base vers le sommet des profils. Si elle est progressive sur le profil IIIb, en revanche sur les séquences du site VIII la transition environnementale est plus tranchée soulignant une interruption dans l'enregistrement malacologique et suggérant un hiatus stratigraphique correspondant au passage de Lg à Lb.

Généralement, la présence de mollusques forestiers, qui sont ici observés dès la base de la séquence, implique des conditions climatiques tempérées de type interglaciaire. Par ailleurs, les malacofaunes de la zone W1 qui comptent quelques thermophiles au sein d'assemblages largement dominés par des espèces de milieu ouvert pourraient être rapprochées dans les référentiels malacologiques des régions avoisinantes de la description des malacocénoses du début de l'Holocène (Preece \& Bridgland, 1999; Limondin, 1995). Cependant cette interprétation n'est pas recevable car elle apparaît en contradiction avec 


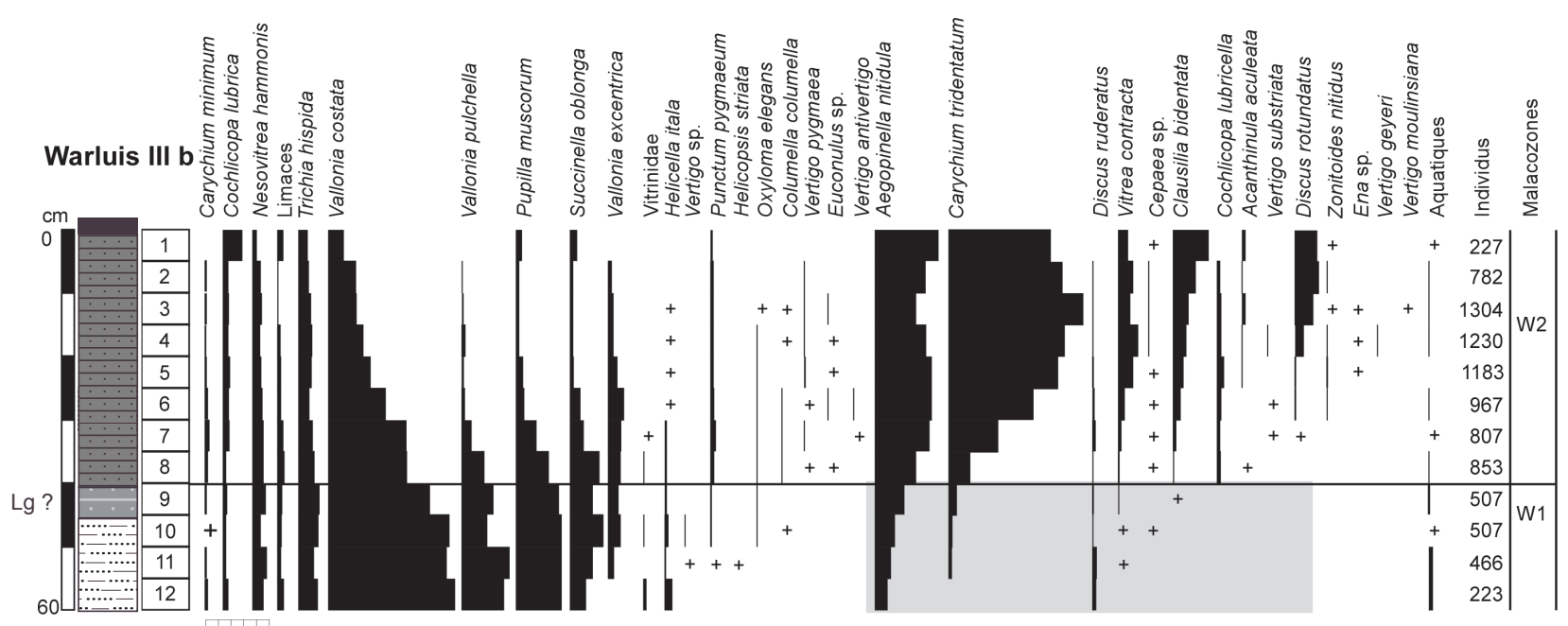

$0 \quad 20 \%$
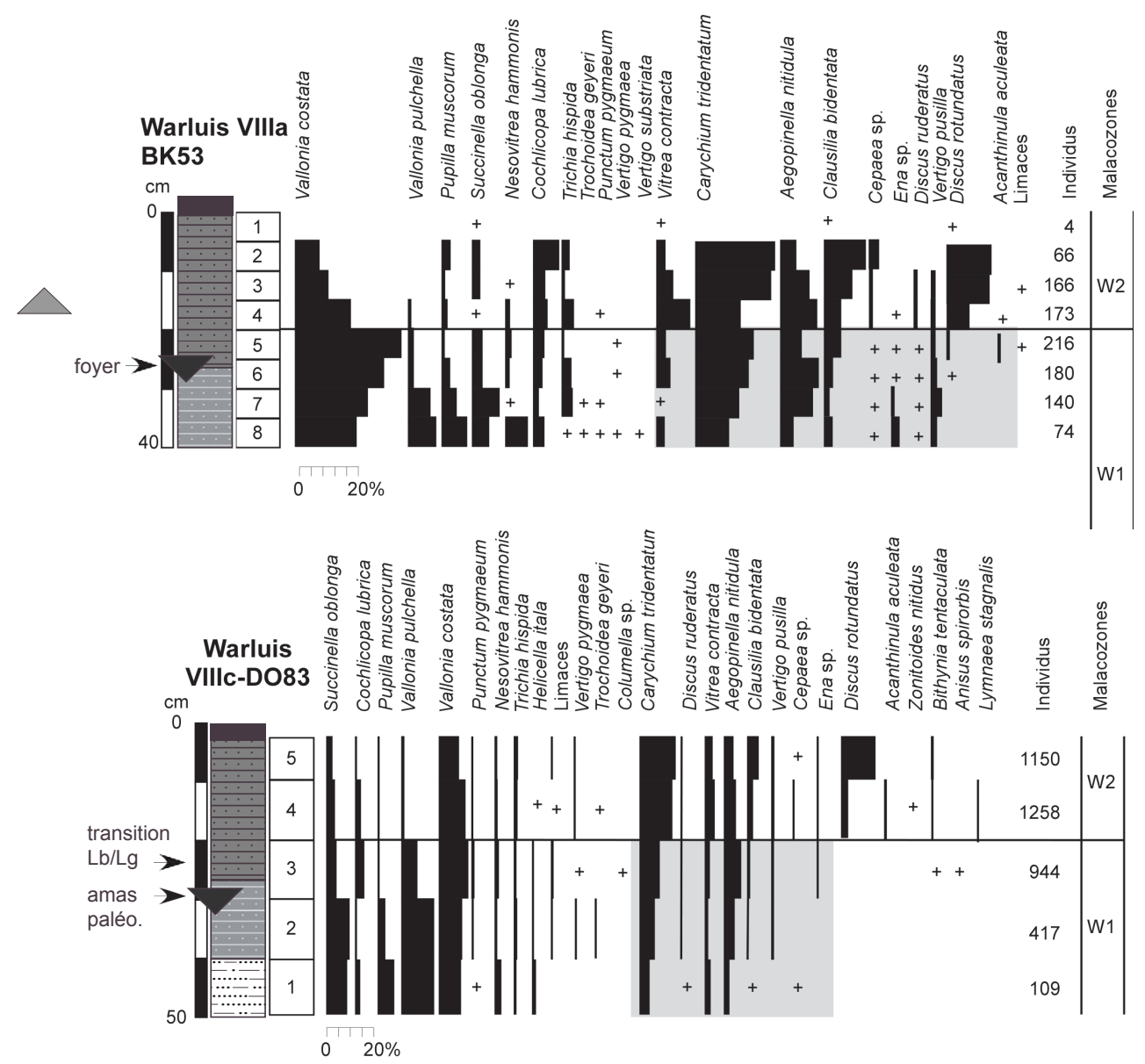

Fig. 11 : Diagramme malacologique de Warluis IIIb, VIIIa et VIIIc.

Les croix représentent un seul individu. La zone grisée signale les espèces intrusives de l'Holocène.

Fig. 1: Malacological diagram from Warluis IIIb, VIIIa and VIIIc. Crosses represent single shells. Grey area is used to show Holocene intrusive species.

l'attribution chronologique des dépôts liée à la présence de niveaux archéologiques du Paléolithique final en place dans le niveau de limon sableux gris ( $\mathrm{Lg}$ ), en équivalence avec les assemblages de la malacozone W1.

Au sommet des profils, les faunes de la zone W2 présentent une structure indubitable d'assemblages de phase tempérée qui s'appuie sur l'expansion des forestiers dont les proportions s'élèvent rapidement à plus du tiers des associations, le développement des hygrophiles égale- ment dépendants d'un couvert végétal dense et fermé et le retrait des taxons de zone ouverte qui dominent dans les environnements du Tardiglaciaire. Cette attribution à l'Holocène est en accord avec la présence de niveaux du Mésolithique.

\section{Discussion et interprétation}

Les diagrammes malacologiques détaillés (fig. 11) mettent en valeur les variations au niveau spécifique 


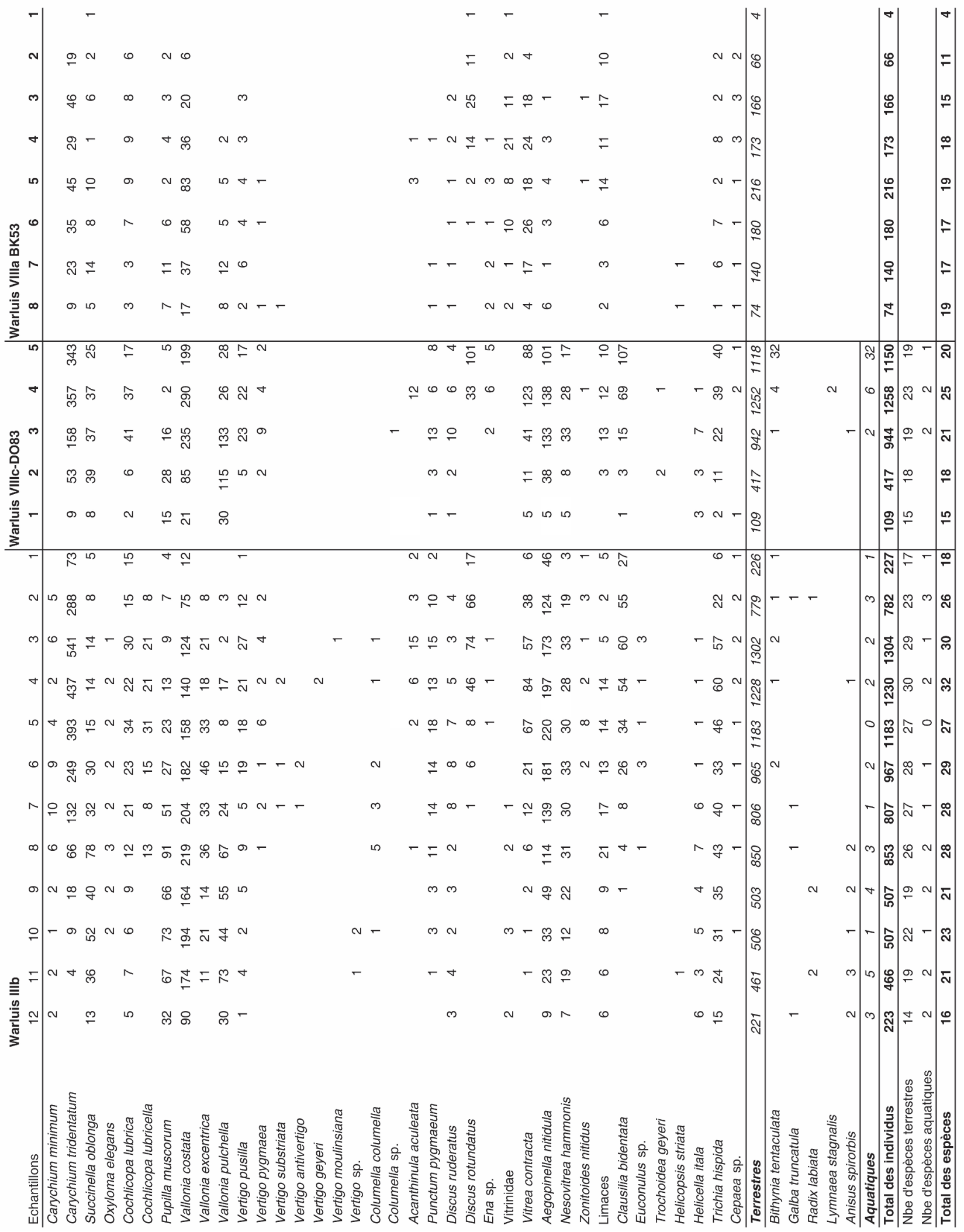


et permettent de discuter en détail les occurrences de plusieurs mollusques caractéristiques des malacocénoses de la transition Tardiglaciaire/Holocène.

Dans la zone W1 les assemblages présentent une structure fortement héritée du Tardiglaciaire avec la dominance de taxons pionniers de milieu ouvert tels que Vallonia costata, Vallonia pulchella, Pupilla muscorum, Trichia hispida, Succinella oblonga (Limondin-Lozouet, 2002). Le cortège secondaire qui les accompagne est composé par des taxons mésophiles qui apparaissent dans les successions malacologiques régionales au cours des interstades du Tardiglaciaire (Carychium minimum, Cochlicopa lubrica, Nesovitrea hammonis, Vitrina, Punctum pygmaeum, Vitrea contracta) et par des espèces xérophiles qui caractérisent plus précisément l'oscillation de l'Allerød (Helicella itala, Helicopsis striata, Trochoidea geyeri) dans les vallées du Nord de la France (Limondin, 1995; Limondin-Lozouet, 1997, 1998). Ces cortèges secondaires disparaissent pendant le Dryas récent qui se marque régionalement, ainsi qu'à l'échelle du Nord-Ouest de l'Europe, par l'appauvrissement spécifique des populations malacologiques et l'occurrence de taxons boréo-alpins tels que Columella columella (Limondin-Lozouet \& Antoine, 2001; Limondin-Lozouet, 2002). Enfin, au début de 1'Holocène, les mésophiles réapparaissent en même temps que les premières espèces thermophiles, alors que les mollusques xérophiles caractéristiques de l'Allerød ne sont plus recensés. Parmi ces derniers, $H$. striata et $T$. geyeri, qui présentent des aires de répartition modernes très déconnectées du Nord de la France, constituent des repères biostratigraphiques importants de l'Allerød (Limondin, 1995 ; Limondin-Lozouet, 1998).

Par ailleurs les assemblages de la première zone de Warluis comportent également un petit pourcentage de mollusques thermophiles (Aegopinella nitidula, Carychium tridentatum, Discus ruderatus) qui ne sont jamais présents dans les successions malacologiques du Tardiglaciaire (Limondin-Lozouet, 1998, 2002; Preece \& Bridgland, 1999; Meyrick, 2001).

Ces assemblages atypiques ne peuvent se comprendre que si l'on admet la pollution des niveaux tardiglaciaires par les faunes holocènes, liée à une forte activité biologique dans les sols dès le début du Postglaciaire. Les espèces qui ont certainement «migré» vers les échantillons de la zone W1 sont les forestiers (fig. 11) mais il n'est pas exclu que ce phénomène ait affecté également en partie les effectifs des autres taxons sans qu'il soit possible de déchiffrer ce palimpseste. Cette interprétation implique l'existence d'un hiatus sédimentaire correspondant au Dryas récent, invisible en stratigraphie car la discontinuité a été littéralement gommée par la forte bioturbation (observée en macroscopie mais également sur les lames minces prélevées dans les limons). Dans les cortèges malacologiques, on remarque une occurrence de Columella columella sur le profil Warluis IIIb (fig. 11) à la limite des deux malacozones qui pourrait constituer la seule trace tangible de cet épisode froid.
Une situation tout à fait analogue a déjà été observée sur des gisements de la vallée de la Somme. Plusieurs séquences, à occupations du Paléolithique et du Mésolithique, situées à l'amorce du versant, présentent une superposition directe du sol Allerød par les dépôts du début de l'Holocène dont la conséquence directe est la pollution des cortèges biologiques (malacologiques et palynologiques) du Tardiglaciaire par des apports du début du Postglaciaire (Limondin, 1995; Antoine et al., 2000).

Dans le limon brun Lb auquel correspond la malacozone W2, les rares mollusques xérophiles (Helicopsis striata, Helicella itala, Trochoidea geyeri) disparaissent. A l'inverse les espèces de biotopes fermés déjà présentes en W1 se développent et leur cortège s'enrichit (Clausilia bidentata, Acanthinula aculeata, Discus rotundatus, Zonitoides nitidus, Ena); de même l'hygrophile Carychium tridentatum, typique des humus forestiers, connait une expansion marquée. Dès la base de la zone W2, les mollusques inféodés au milieu forestier représentent 20 à $25 \%$ des effectifs, et cette proportion va croitre régulièrement jusqu'au sommet des séquences (fig. 11). En parallèle, les mollusques de milieux ouverts (les Vallonia et Pupilla muscorum) diminuent fortement. Des faunes semblables ont été identifiées dans les successions malacologiques du Nord-Ouest de l'Europe au début de l'Holocène (Limondin-Lozouet, 1995, 1997; Preece \& Bridgland, 1999; Meyrick, 2000). Toutefois l'occurrence des deux espèces du genre Discus, discutée ci-après, apporte des éléments chronologiques plus précis.

Parmi les premiers mollusques thermophiles recensés à Warluis, la présence de Discus ruderatus est particulièrement intéressante. Cette espèce est aujourd'hui typique des forêts anciennes en Europe septentrionale et en altitude dans les massifs montagneux (Kerney et al., 1983). Sa répartition holocène en Europe du Nord-Ouest la désigne comme une espèce pionnière des biotopes fermés du début de l'interglaciaire. Les études de plusieurs séquences de Grande-Bretagne, du Luxembourg et d'Allemagne (Preece \& Day, 1994; Preece \& Bridgland, 1999; Meyrick, 2000, 2001; Meyrick \& Preece, 2001) ont montré que le remplacement de Discus ruderatus par son congénère Discus rotundatus est caractéristique des séries malacologiques du début de l'Holocène et peut être corrélé avec l'expansion progressive du couvert forestier. D. ruderatus apparait invariablement dans des assemblages de forêt ouverte tandis que le développement de D. rotundatus survient lorsque la couverture arborée se densifie. Le passage d'une espèce à l'autre est plus ou moins marqué selon les séries; il peut être soit brutal comme à Holywell Coombe et Slidings Copse (Preece \& Bridgland, 1999; Preece \& Day, 1994) soit progressif comme à Courteenhall et Weston Favell (Meyrick \& Preece, 2001) où les deux espèces coexistent dans quelques échantillons comme c'est le cas à Warluis.

Outre son aspect environnemental, cette succession est également intéressante pour sa valeur chronologique car plusieurs datations lui sont rattachées. L'occurrence de D. ruderatus est datée aux alentours de 9700 BP en Allemagne et de 9500 BP en Grande-Bretagne (Meyrick, 
2001; Preece \& Bridgland, 1999). Le développement de $D$. rotundatus peut être calé vers 8500 et $8400 \mathrm{BP}$ au Luxembourg et en Allemagne et s'il est recensé dès 8990 \pm 90 BP dans l'Oxfordshire (Preece \& Day, 1994), la plupart des dates obtenues dans le sud-est de la GrandeBretagne situent son essor autour de 8600 BP. Dans le nord du Pays de Galles et en Irlande, son expansion est légèrement plus tardive, et a été datée respectivement de 8300 et 8100 BP (Preece, 1997).

En France, la succession D. ruderatus/D. rotundatus a été observée dans la zone alpine (Chaix, 1986, 1988). Sa signification environnementale est similaire à celle donnée pour les zones plus septentrionales; en revanche, la situation en altitude est plus favorable à $D$. ruderatus et son retrait au profit de $D$. rotundatus s'en trouve retardé aux alentours de 7500 BP. Dans la vallée de la Somme, D. ruderatus a été recensé sur plusieurs gisements (Limondin, 1995) mais toujours en association avec $D$. rotundatus dans des niveaux attribués au début du Boréal vers $8830 \pm 90 \mathrm{BP}$ pour la date la plus ancienne. Ensuite, à partir de $8645 \pm 70 \mathrm{BP}$, les assemblages de la Somme ne contiennent plus que $D$. rotundatus. Le plus souvent la phase holocène la plus ancienne n'est pas représentée sur les séquences de la Somme (Limondin, 1995). Le site de Conty dans la vallée de la Selle est un des rares à livrer des dépôts du Préboréal, lesquels, calés entre $9720 \pm 130 \mathrm{BP}$ et $9310 \pm 60 \mathrm{BP}$, contiennent des assemblages malacologiques avec quelques thermophiles pionniers mais sans Discus (Limondin-Lozouet \& Antoine, 2001). Dans une région proche, la succession malacologique du tuf holocène de Saint Germain-le-Vasson en Normandie (Limondin-Lozouet \& Preece, 2004) atteste du développement de Discus rotundatus à $9074 \pm 63$ BP en correspondance avec l'essor de Corylus qui caractérise le Boréal (Limondin-Lozouet et al., 2005).

Pour le nord de la France, Warluis IIIb est la première séquence qui montre la succession de ces deux espèces. D'après les datations obtenues dans les zones plus septentrionales, on peut supposer que l'apparition de $D$. ruderatus en Picardie précède son arrivée en Grande-Bretagne (9500 BP) et est au moins équivalente à sa plus ancienne occurrence en Allemagne (9700 BP). Cependant la première notation de Discus ruderatus dans la séquence de Warluis ne peut pas être positionnée avec exactitude sur les profils étudiés à ce jour, trop marqués par la bioturbation. En revanche, le développement de $D$. rotundatus, qui se place dans les échantillons sommitaux (Lb), est en position stratigraphique fiable. D'après les données observées dans les régions proches, l'essor de $D$. rotundatus est contemporain de l'extension d'un couvert forestier plus dense, qui peut être placé au moins vers 8900 BP par comparaison avec la date la plus ancienne obtenue en GrandeBretagne (Preece \& Day, 1994), voire antérieurement selon la date de Normandie (9074 \pm 63 BP, LimondinLozouet \& Preece, 2004). Cette hypothèse apparaît en outre en bonne adéquation avec les dates sur os obtenues au sommet du limon brun ( $\mathrm{Lb}$ ) ou à la base de la tourbe $(\mathrm{T})$ sur le site de Warluis III, respectivement $8760 \pm 60 \mathrm{BP}$ et $8766 \pm 65 \mathrm{BP}$.

\section{Conclusion}

Les premiers résultats de l'étude des malacofaunes de Warluis permettent de poser plusieurs points de repères.

- Bien que très bioturbée, la succession sédimentaire est l'expression de la transition Tardiglaciaire/début Holocène et les cortèges malacologiques montrent clairement une évolution environnementale vers la densification du couvert végétal.

- Les niveaux sableux de la base des profils (Lsbj) sont à rattacher au Tardiglaciaire car leurs assemblages malacologiques contiennent des populations développées de Vallonia qui constituent un élément caractéristique de cette période (Limondin, 1995).

- La présence d'un cortège d'espèces xérophiles (H. striata, T. geyeri, H. itala) incite à proposer un rattachement à l'Allerød au moins pour le niveau de limon gris $(\mathrm{Lg})$.

- La composition et l'évolution des cortèges impliquent un hiatus sédimentaire correspondant au Dryas récent.

- La succession des deux espèces du genre Discus témoigne du passage Préboréal/Boréal. Si l'apparition de D. ruderatus ne peut être positionnée avec fiabilité au sein de la séquence, le développement de $D$. rotundatus permet en revanche d'attribuer le sommet des profils ( $\mathrm{Lb}$ ) au début du Boréal.

- Le niveau de foyer sur le profil VIIIa et l'industrie du profil VIIIc apparaissent inclus dans la malacozone W1 et sont donc attribuables sans équivoque au Tardiglaciaire.

Il reste encore plusieurs séries malacologiques à étudier sur le site de Warluis dont les résultats permettront sans doute de résoudre certaines interrogations ou de confirmer les attributions et conclusions proposées à partir de cette première approche.

\section{3 - LES MAMMIFÈRES}

Les corpus fauniques des sites de Warluis sont en cours d'étude. Seuls des résultats préliminaires concernant les sites IIIb, II et I ont été publiés (Ducrocq et al., 2008). Les données présentées ici concernent plus spécifiquement la signification paléoenvironnementale des spectres fauniques plutôt que les aspects palethnologiques. Une partie des vestiges correspond d'ailleurs vraisemblablement à des apports non anthropiques.

Dans l'état actuel des recherches, le spectre faunique de l'occupation initiale du site IIIb, attribuable au Préboréal et inclus dans $\mathrm{Lb}$, comprend 4 espèces d'ongulés, 2 espèces de petits mammifères et un reste d'oiseau (Aves indét.) (tab. 5). Le cerf (Cervus elaphus) compte pour $60 \%$ des restes environ. Il s'agit d'une femelle âgée d'environ 4 ans représentée par des restes crâniens, par certains os des membres, par un fragment de bassin ainsi que par des côtes. Le chevreuil (Capreolus capreolus), avec $13 \%$ des restes, est représenté par des fragments de métapodes, de radius et de coxal, par des dents et par des fragments de massacre et d'andouiller. La ramure indique qu'il s'agit d'un six cors, soit un mâle de plus de deux ans. L'aurochs (Bos primigenius) est la troisième espèce représentée avec des restes d'os longs et de dents. 


\begin{tabular}{|l|l|l|l|}
\hline Espèces & NR & \%NR & NMIi \\
\hline Cervus elaphus (Cerf élaphe) & 54 & 59,3 & 1 \\
\hline Cf. Cervus elaphus & 4 & 4,4 & \\
\hline Bos primigenius (Aurochs) & 6 & 6,6 & 1 \\
\hline Bos Cf. primigenius & 3 & 3,3 & \\
\hline Sus scrofa (Sanglier) & 5 & 5 & 2 \\
\hline Capreolus capreolus (Chevreuil) & 12 & 13,2 & 2 \\
\hline Castor fiber (Castor) & 5 & 5,5 & 1 \\
\hline $\begin{array}{l}\text { Vulpes vulpes ou Canis familiaris } \\
\text { (Renard ou chien) }\end{array}$ & 1 & 1,1 & 1 \\
\hline Aves (oiseaux indéterminés) & 1 & 1 & 1 \\
\hline Total déterminés & $\mathbf{9 1}$ & $\mathbf{1 0 0}$ & $\mathbf{9}$ \\
\hline
\end{tabular}

Tab. 5 : Spectre faunique du site IIIb (bois inclus).

NMIi : nombre minimal d'individus par individualisation, c'est-à-dire en tenant compte des âges dentaire et squelettique.

Tab. 5: Faunal spectrum of site IIIb (antlers included). NMIi: minimal number of individuals by individualization, i.e. taking into account dental and skeletal ages.

Le sanglier est peu abondant (deux individus). Le castor (Castor fiber) est présent, ainsi qu'un petit canidé (renard ou chien).

Sur les sites II et I (tab. 6), attribuables à la fin du Préboréal ou au tout début du Boréal, les spectres fauniques sont caractérisés par une faible diversité spécifique, dominée par le sanglier (Sus scrofa), en dépit du tamisage des sédiments. Sur le site II, inclus dans Lb, quelques restes de cerf (Cervus elaphus), de chevreuil (Capreolus capreolus), de castor, de renard et de blaireau sont également présents.

Le sanglier est l'unique espèce de grande faune recensée sur Warluis I (site de zone haute). Elle est documentée par une centaine de restes. Au moins 4 individus sont identifiés sur la base des âges dentaires (un animal d'environ 5-9 ans, deux individus de 25-27 mois et un juvénile autour d'1 an).

Parmi les ossements issus d'apports naturels au sommet des limons bruns $\mathrm{Lb}$ ou à la base de la tourbe $\mathrm{T}$, figurent le sanglier (IIc, $8810 \pm 70 \mathrm{BP}$ ), le chevreuil (IIIb, $8766 \pm 65$ BP), le cerf (IIIb, $8490 \pm 60$ BP). Du cerf a également été retrouvé en surface de la tourbe (IIIb, 6930 $\pm 50 \mathrm{BP})$.
Les ensembles fauniques de Warluis présentent donc des situations contrastées au niveau de la composition spécifique: prépondérance du cerf (IIIb) ou du chevreuil (IIIa) dans la phase ancienne, prépondérance du sanglier dans les concentrations plus récentes du début du Boréal (sites I et II). L'abondance des suidés a été aussi observée dans le bassin de la Somme dans les corpus fauniques calés dans la chronozone du Boréal (Bridault, 1997). Ce changement de la composition faunique est à mettre en parallèle avec la présence de nombreuses noisettes carbonisées sur les sites les plus récents (I, II et IV), ces deux éléments étant corrélés à l'extension de la corylaie visible en palynologie (représentation maximale de Corylus dans la zone war $\mathrm{c} 1$ ).

Ces contrastes inter-sites doivent être interprétés au regard de plusieurs facteurs, notamment:

- les transformations écologiques du début de l'Holocène, marquées par l'extension du couvert forestier et une dynamique des populations animales jouant sur l'abondance de certaines ressources dans l'environnement des sites. L'hypothèse déjà évoquée d'un accroissement démographique du sanglier (Bridault, 1997), espèce prolifique, n'est pas contredite par ces nouvelles données: l'importance significative du sanglier s'enregistre, dans différentes régions, à partir du Boréal;

- la nature des activités et la fonction du site à l'échelle du mode d'exploitation des territoires (en relation avec la saisonnalité des occupations). Il est ainsi frappant de constater le peu de vestiges de poissons sur ces sites à proximité immédiate des cours d'eau.

\section{6 - LES DATATIONS RADIOCARBONE}

Les calibrations des dates sont données dans le tableau 1 et la figure 12 .

\section{1 - LES DATATIONS SUR LE COMBLEMENT DES CHENAUX}

Deux chenaux ont fait l'objet de datations: le chenal tardiglaciaire de Rochy-Condé (chenal 1) et le chenal 3 (tab. 1).

\begin{tabular}{|l|c|c|c|c|c|c|}
\hline & \multicolumn{3}{|c|}{ W I } & W II b & W IIc & W II d \\
\hline Espèces & NR & \% NR & NMIi & & & \\
\hline Sus scrofa (Sanglier) & 88 & & 4 & ++ & ++ & ++ \\
\hline Cervus elaphus (Cerf élaphe) & & & & + & + & \\
\hline Capreolus capreolus (Chevreuil) & & & & & + & + ? \\
\hline Vulpes vulpes (Renard roux) & & & & & + & + \\
\hline Meles meles (Blaireau) & 12 & & & & & + \\
\hline Castor fiber (Castor) & 5 & & & $+?$ & + & \\
\hline Côtes cf. Sus scrofa & 11 & & & & & \\
\hline Vertèbre cf. Sus scrofa & 8 & & & & & \\
\hline Total déterminés & $\mathbf{1 0 2}$ & $\mathbf{1 0 0}$ & $\mathbf{9}$ & $<\mathbf{2 0}$ & $>\mathbf{2 0}$ & $\sim \mathbf{7 0}$ \\
\hline++ : abondant, + : présent, +? association avec occupation méso. incertaine \\
\hline
\end{tabular}

Tab.6 : Spectre faunique des sites I et II.

NMIi : nombre minimal d'individus par individualisation, c'est-à-dire en tenant compte des âges dentaire et squelettique.

Tab. 6: Faunal spectrum of sites I and II. NMIi: minimal number of individuals by individualization, i.e. taking into account dental and skeletal ages. 
(dg ןеo) sәəุıq!|eo səə઼uue

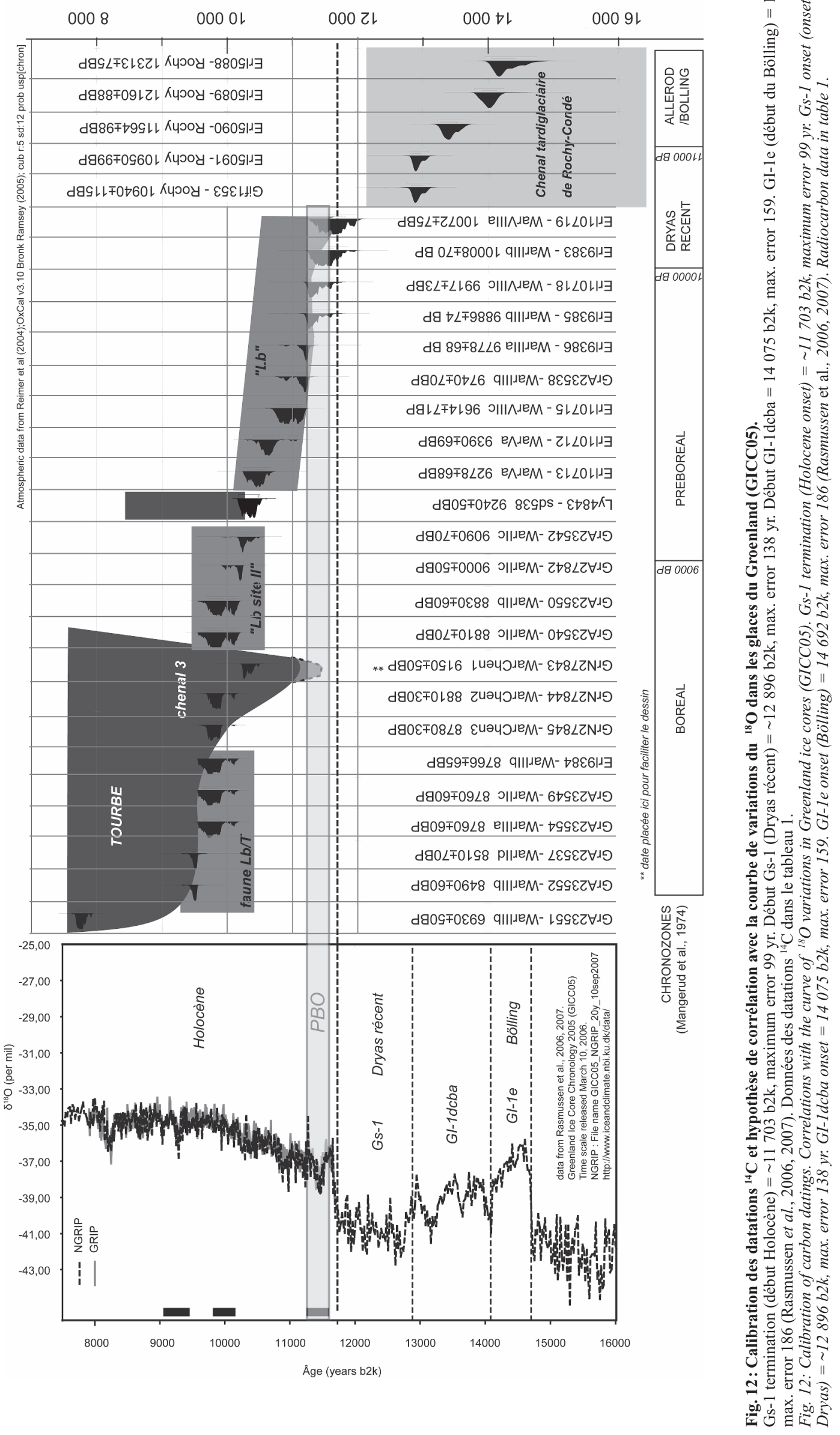


Le faciès limono-calcaire présent dans le chenal de Rochy-Condé (chenal 1) est caractéristique du Dryas récent dans la moitié nord de la France (Pastre et al., 2003; Antoine et al., 2003). Les datations radiocarbone sur les sédiments organo-détritiques sous-jacents, attribuables au Bølling et à l'Allerød, confirment cette attribution (tab.1, fig. 3).

La phase de tourbification franche se place avant $12313 \pm 75$ BP (Er15088).

Le comblement du chenal 3 a fait l'objet de 3 datations sur la partie supérieure de la sédimentation tourbeuse, sur bois flottés (fig. 3 et 6). Une petite phase de sédimentation détritique (argile limoneuse grise) intercalée dans les tourbes a été datée à $9150 \pm 50 \mathrm{BP}$ (GrN27843). L'étude palynologique confirme l'attribution des tourbes situées sous cette argile grise au Préboréal (zone War b-2).

\section{2 - LES DATATIONS SUR LES SITES ARCHÉO- LOGIQUES}

Les datations ont été effectuées sur des noisettes carbonisées et des restes fauniques clairement associés à l'industrie lithique (tab. 1). Aucun vestige n'a permis de dater les occupations du Paléolithique final à Federmesser.

En l'état actuel des études, la date la plus ancienne pour une occupation post-glaciaire, $10072 \pm 75 \mathrm{BP}$ (site VIIIa, Erl10719), a été obtenue sur le site VIIIa, positionné autour de la limite $\mathrm{Lb} / \mathrm{Lg}$. Sur le site IIIa, dans la même position stratigraphique, une date donne $9778 \pm 68 \mathrm{BP}$ (site IIIa, Er19386), c'est-à-dire au début du Préboréal. La date la plus récente est de $8510 \pm 70$ (site IId, GrA23537). Les autres dates sur les sites archéologiques concernent le Préboréal et le Boréal (tab.1).

\section{3 - LES DATATIONS SUR LA FAUNE D'APPORT NATUREL}

Quelques dates ont été également réalisées sur des ossements animaux mis en place par apport naturel au sommet des limons bruns $\mathrm{Lb}$ ou en base de la tourbe $\left(\mathrm{T}, \mathrm{n}^{\circ}\right.$ 3) : $8490 \pm 60 \mathrm{BP}$ (GrA23552, site IIIb), $8760 \pm 60$ BP (GrA23554, site IIIa), $8766 \pm 65$ BP (GrAEr19384, site IIIb), $8810 \pm 70$ BP (GrA23540, site IIc). Ces datations placent l'extension de la tourbière dans les zones basses au cours du Boréal.

\section{7 - CHRONOSTRATIGRAPHIE ET ÉVOLUTION PALÉOENVIRONNEMENTALE}

L'organisation du fond de vallée est structurée par l'héritage pléniglaciaire, matérialisé par les dômes de graviers. La topographie s'est trouvée adoucie par les dépôts tardiglaciaires et les chenaux holocènes ont ré-incisé l'ensemble de manière apparemment plus localisée. Par exemple, dans la partie sud de la carrière, la zone très basse présente des dépôts du Dryas récent qui semblent érodés dans l'axe du chenal holocène principal.
La grave de fond est généralement recouverte de sables limoneux blanchâtres (Lsbj). Sur les profils étudiés en malacologie ainsi que dans le diagramme pollinique du chenal 3, il apparaît qu'au moins la partie supérieure de ces sables (Lsbj) est attribuable au Tardiglaciaire (présence de Vallonia, zone pollinique War a1 indiquant un paysage très ouvert) et non au Pléniglaciaire comme il était supposé au départ.

\section{1 - BØLLING ET ALLERØD}

La période tardiglaciaire semble être caractérisée par un chenal principal, le seul qui ait été repéré sur le tracé du gazoduc (fig. 4). Ce chenal est incisé dans la grave ou dans des dépôts plus fins pléniglaciaires ou tardiglaciaires. Il est large d'au moins une vingtaine de mètres à Rochy-Condé (chenal 1, en partie sous la voie ferrée).

Le chenal tardiglaciaire principal a également été repéré en sondages sur la carrière de Warluis (chenal 2, fig. 4).

Le chenal 3 est quant à lui un chenal secondaire actif dès le Tardiglaciaire. Sa base est remblayée par des sédiments limoneux argilo-sableux et limono-organiques (Lsbj et $\mathrm{Lg}$ ) rapportés au Dryas ancien, au Bølling et à l'Allerod d'après l'étude palynologique. Cela s'accorde avec les résultats ${ }^{14} \mathrm{C}$ obtenus à la base du paléochenal 1 reconnu à Rochy-Condé (fig. 3) le long de la limite nord de l'emprise de Warluis (Pastre et al., 2003). La poursuite des analyses polliniques sur la séquence du chenal 3 (resserrement des échantillons analysés) devrait préciser cette attribution chronostratigraphique.

Le chenal 1 de Rochy-Condé présente également des formations organiques datées de l'Allerød (Pastre et al., 2003), plus détritiques que les formations du Bølling. Cette tendance au détritisme s'accorde avec celle identifiée dans le chenal 3. Dans ce dernier, les sédiments rapportés à l'Allerød sur la base d'arguments palynologiques (zone pollinique War a) et stratigraphiques sont des limons gris moyen à clair $(\mathrm{Lg})$. Il n'a pas été identifié de tourbes Allerød.

En-dehors des chenaux, la présence de sédiments d'âge Allerød est pressentie sur les sites VI, VII, VIII et IX du fait de la présence d'industrie du Paléolithique final à Federmesser (Fagnart \& Coudret, 2000) en place dans les limons gris Lg. Sur le site III, l'industrie à Federmesser est absente mais le passage latéral avec les formations du chenal 3 a été observé. Cette attribution du Lg des zones basses à l'Allerød est appuyée par l'analyse malacologique effectuée sur les sites III et VIII (malacozone W1). Leur couleur grise témoigne de l'incorporation de matière organique. La bioturbation est visible en lame mince. Les cortèges malacologiques indiquent des environnements ouverts avec une végétation au sol assez couvrante, modérément humides, qui supposent un milieu bien drainé permettant l'existence de quelques espèces xérophiles caractéristiques de l'Allerød. Cela coïncide avec le développement de la végétation tel qu'il est perçu dans le chenal 3 (palynozone War a2 et 3), caractérisée par la coexistence d'une prairie humide et d'une steppe à armoise, ainsi que de boisements clairs à bouleaux et pins (fig. 13). 

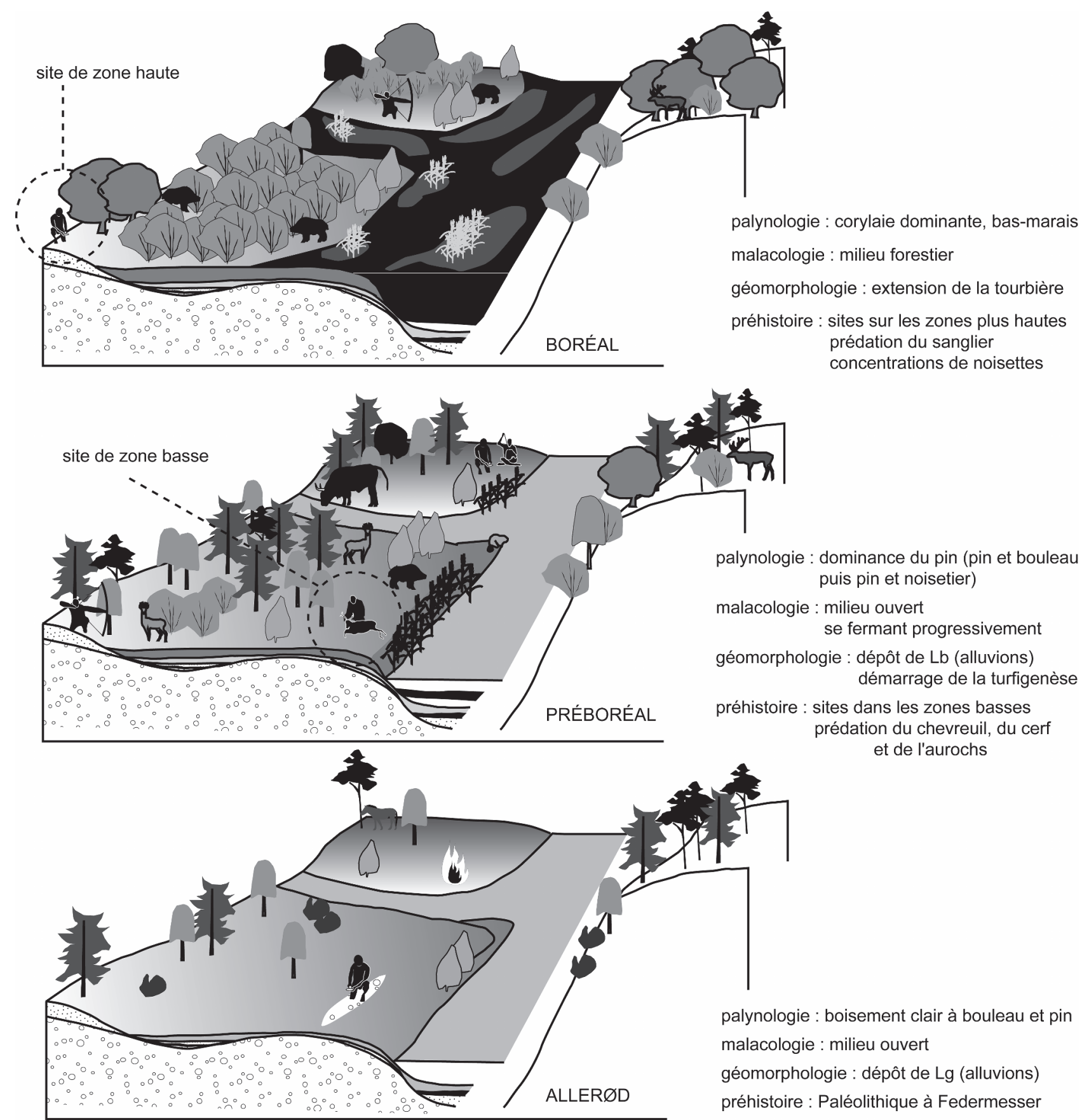
et de l'aurochs

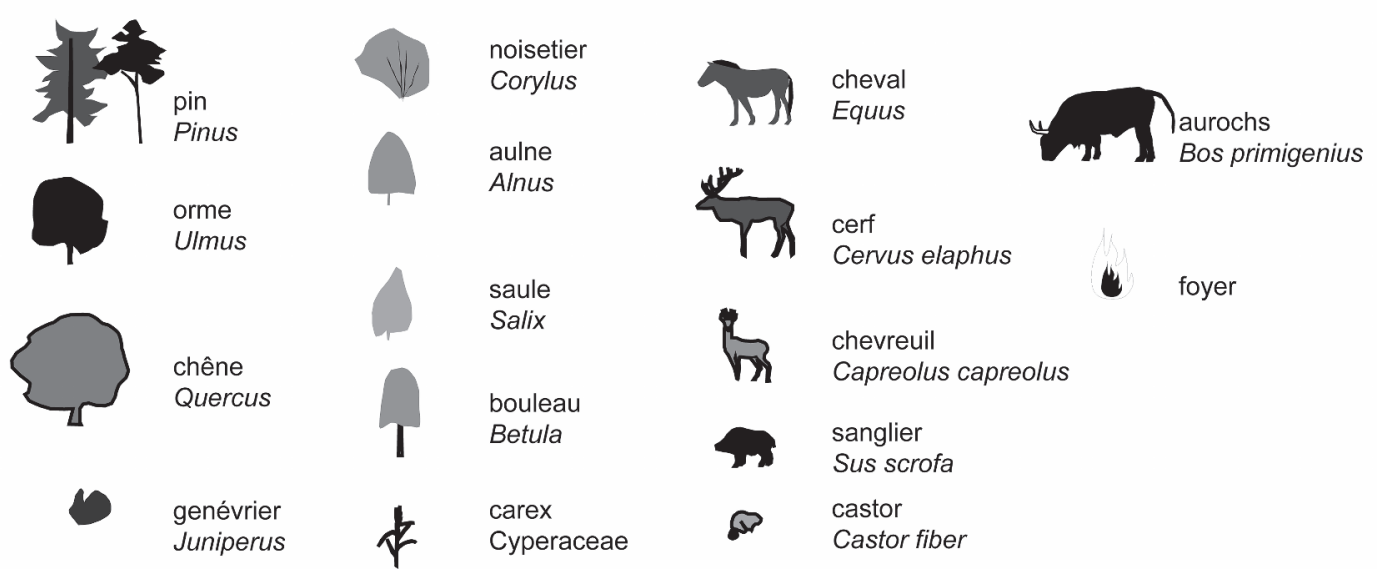

Fig. 13 : Reconstitution paléoenvironnmentale schématique pour l'Allerød, le Préboréal et le Boréal à Warluis. Fig. 13: Palaeoenvironmental reconstruction at Warluis for the Allerød, the Preboreal and the Boreal periods. 
L'ensemble des éléments issus des différentes analyses convergent vers l'identification pour l'Allerød d'un sol alluvial probablement cumulique. Cette pédogenèse Allerød marque une stabilisation régulière de la plaine alluviale.

Le sol Allerød a par ailleurs été identifié ponctuellement sur le site II de Warluis sous le faciès plus typique de limons sableux gris foncé recouverts de limons calcaires attribuables au Dryas récent. Il n'y a pas d'analyse malacologique pour corroborer cette attribution sur base géomorphologique.

Ce sol est reconnu largement dans le Bassin parisien (Pastre et al., 2000, 2003) mais également en Angleterre (Preece \& Bridgland, 1999). Dans le bassin de la Somme, les sols Allerød (sols construits légèrement humifères) ont été observés en bas de versants, où ils sont développés sur des colluvions limoneuses ruisselées riches en granules de craie. Helicopsis striata, espèce de mollusque inféodée aux milieux secs, est un repère dans ce secteur (Limondin, 1995, Antoine, 1997, Antoine et al., 2000). A Warluis, sa présence très ponctuelle (uniquement éch. 11 de Warluis IIIb et éch. 7 et 8 de Warluis VIIIa, à la base de la malacozone W1), traduit des conditions plus humides, comme à Conty (Limondin-Lozouet \& Antoine, 2001; Antoine et al., 2000). Ces conditions plus humides s'expliquent aussi par une différence dans les contextes étudiés: bas de versants dans la vallée de la Somme, fond de vallée pour Warluis.

\section{2 - LE DRYAS RÉCENT}

Les sédiments du Dryas récent, caractérisés par un faciès limoneux calcaire (Lcalc, $n^{\circ} 5$ ), ont été repérés dans les chenaux et dans les parties nord-ouest et sud de la carrière (fig. 4). L'attribution chronologique est basée pour une part sur l'identité de faciès avec l'ensemble des dépôts Dryas récent connus par ailleurs, cette phase de sédimentation à haute teneur en carbonate caractérisant le Dryas récent dans l'ensemble du Bassin parisien (Pastre et al., 1997, 2000, 2003), dans le bassin de la Somme (Antoine et al., 2003) et les régions crayeuses du sudouest de l'Angleterre (Preece \& Bridgland, 1999).

Les limons calcaires (Lcalc) sont bien développés dans le chenal 1 de Rochy-Condé, où le colmatage atteint un mètre. Sur ce site, l'attribution au Dryas récent est confirmée par les datations sur les sédiments sous-jacents. Dans le chenal 3 (site III), les limons calcaires blancs (Lcalc) n'atteignent qu'une vingtaine de centimètres d'épaisseur. Le Dryas récent n'apparaît pas clairement dans le profil palynologique mais le nombre d'échantillons est très réduit ( 4 échantillons pour la séquence tardiglaciaire). Les sédiments calcaires sont néanmoins compris entre des sédiments attribués à l'Allerød et des sédiments attribués au Préboréal (fig. 9). En dehors des chenaux, ces limons sont présents sur une faible épaisseur sur le site II, et sur une large surface dans la partie sud de la carrière (fig. 4), qui est plus basse en altitude.

Ces sédiments n'ont pas été reconnus dans le reste de la carrière; cette absence correspond probablement à un hiatus sédimentaire. Cette hypothèse est corroborée par l'analyse malacologique qui signale une rupture entre les malacozones W1 et W2, c'est-à-dire entre les unités Lg (Allerød) et Lb (Préboréal-Boréal). De minces dépôts ont cependant pu être mélangés aux autres niveaux par la pédogenèse préboréale et boréale. Le Dryas récent semble donc avoir un impact limité dans ce secteur de la vallée du Thérain. On peut imaginer des dépôts circonscrits à un chenal et ses abords.

\section{3 - LE DÉBUT HOLOCÈNE (PRÉBORÉAL ET BORÉAL)}

Au début de l'Holocène, la plaine alluviale est traversée par plusieurs chenaux. Les plus profonds peuvent reprendre le tracé des chenaux tardiglaciaires, l'érosion des dépôts du Dryas récent rendant alors impossible en sondages la distinction entre dépôts tardiglaciaires et holocènes. Ce serait le cas dans la partie sud de la carrière où le chenal 2 tardiglaciaire n'a pas été repéré en continu (fig. 4). Il est en effet courant que les chenaux du Préboréal reprennent des tracés préexistants en érodant leur contenu (Antoine, 1997).

Ces chenaux sont essentiellement tourbeux mais le détritisme est encore important dans les premières phases des remplissages (limons tourbeux, formations limonoorganique litées...). Dans le chenal 3, la base du comblement holocène, attribuable au Préboréal d'après l'étude palynologique (zone War b1) est composée de limons sableux.

La tourbification ne débute donc pas dès le début du Préboréal dans le chenal 3. D'après les cortèges polliniques du premier niveau tourbeux (zone régionale $\mathrm{IVb}$ ), un âge autour de 9500 BP peut être avancé (Leroyer, 1997). C'est en tout cas antérieur à $9150 \pm 50 \mathrm{BP}$ (fig. 3 et 9). Dans le sondage 538 (partie sud de la carrière), une datation sur un os d'élan permet de caler le passage d'un limon tourbeux à une tourbe franche vers $9240 \pm 50 \mathrm{BP}$ (Ly-4843).

Les tourbes préboréales sont bien reconnues dans le bassin de la Somme, comme à Renancourt où des tourbes ont été datées en fond de chenal à $9840 \pm 60 \mathrm{BP}$ (11410-11 150 cal BP, Ly-8687; Antoine et al., 2003). Ces tourbes alcalines accompagnent l'extension rapide de la végétation au début du Préboréal.

Cette dynamique de turfigenèse se poursuit au cours du Boréal (tourbière basse alcaline). La partie supérieure de la tourbe est clairement attribuée au Boréal dans le chenal 3 (datations radiocarbone et cortèges polliniques). De nombreuses dates montrent en outre que la vallée est progressivement envahie par les tourbes au cours de cette période à l'exception des points les plus hauts (au-dessus de 53,2 m NGF, fig. 5). En effet, les dates réalisées sur de la faune située en limite $\mathrm{Lb} / \mathrm{T}$ ou base de tourbe en dehors des chenaux ont donné $8766 \pm 65 \mathrm{BP}$ (site IIIb, Erl-9384, altitude 52,5 m NGF) et $8490 \pm 60 \mathrm{BP}$ (site IIIb, GrA-23552, 52,55 m NGF). Cette extension générale de la tourbière traduit une hausse de la nappe phréatique et une baisse des apports minéraux, qui sont mises en relation avec le développement de la végétation arborée 
(Antoine et al., 2003). Des fragments de bois flottés ou d'éléments de bois morts sur place lors de la remontée de la nappe phréatique sont d'ailleurs fréquemment présents à la base des tourbes.

En-dehors des chenaux, les limons sableux et les sables limoneux Lb ont été rapportés au Préboréal et au début du Boréal sur la base :

- de l'enregistrement malacologique;

- des datations radiocarbone réalisées sur les occupations mésolithiques incluses dans les sédiments;

- des datations radiocarbone sur la faune déposées selon des processus naturels au sommet du Lb.

Plus précisément, la succession des deux espèces du genre Discus se place durant les phases Préboréal-Boréal, par référence aux données malacologiques du nord-ouest de l'Europe. Les dates extrêmes obtenues pour le dépôt des limons sableux holocènes Lb sont (tab. 1): 10072 $\pm 75 \mathrm{BP}$ sur VIIIa, et $10008 \pm 70$ sur IIIb (pour la base), $8760 \pm 60$ BP sur IIc et $8510 \pm 70$ BP sur IId (au sommet).

Les sédiments Lb sont d'origine principalement alluviale. Les fantômes de litage identifiés en lame mince soutiennent cette hypothèse. La distance au versant est trop importante pour évoquer des apports colluviaux. La teneur en sable résulte de l'abondance de sables dans le bassin-versant proche (sables tertiaires) et dans les sédiments weichseliens. La mise en évidence de surfaces d'occupation mésolithiques implique des phases d'assèchement. Par ailleurs, les malacofaunes contiennent de nombreuses espèces de biotopes fermés, montrant un environnement forestier qui se densifie vers le sommet du dépôt.

Apparaît donc un contraste entre un chenal comblé par des tourbes et des épandages limono-sableux en dehors des chenaux, déposés selon un rythme de sédimentation inconnu. Ces situations sont incompatibles puisque la sédimentation organique implique une chute des apports détritiques et des milieux de dépôt calmes.

L'hypothèse la plus plausible est donc que le dépôt du Lb est contemporain des phases détritiques enregistrées dans le chenal 3 au cours du Préboréal. Le remplissage du chenal 3 témoigne ainsi d'une sédimentation limoneuse au début de l'Holocène (limon recouvert par des tourbes) suivie de quelques crises détritiques, comme celle signée par la passée d'argiles limoneuses grises intercalée entre deux tourbes datée de $9150 \pm 50$ BP. Quelques phases mineures de remobilisation des sables peuvent éventuellement intervenir sans être enregistrées si des écoulements sans charge de fond provoquent une reprise de sables sur les berges et les zones exposées. Une partie de la tourbe pourrait alors être érodée.

La dynamique du fond de vallée au début du Préboréal est donc caractérisée par une forte mobilisation de stocks sableux qui peuvent être issus des dômes antérieurs, des sables sous-jacents, des versants.

Cette hypothèse est-elle compatible avec ce que l'on sait des occupations mésolithiques et de la malacofaune?

La majorité des occupations datées jusqu'à maintenant sont datées du Préboréal (sites III, V et VIII), certaines étant placées à la limite $\mathrm{Lg} / \mathrm{Lb}$, d'autres situées plus franchement dans le Lb. Certaines sont donc bien contemporaines des apports limoneux du chenal 3 (zone War b1). D'autres (site $\mathrm{V}$ en particulier) peuvent correspondre à des phases de stabilisation permettant déjà le développement de la tourbe dans les chenaux (zone War b2).

Au cours du Boréal, le chenal 3 est colmaté uniquement par des tourbes. Ces tourbes sont donc contemporaines de certaines occupations, sur le site II et sur le site III. Dans ces deux cas, les surfaces d'occupation ne sont pas à plus de $10 \mathrm{~cm}$ de profondeur dans le Lb. Le recouvrement de l'industrie n'implique donc pas des apports sédimentaires importants. Cela s'accorde avec l'évolution des cortèges malacologiques: la malacofaune indique pour la partie supérieure de Lb un environnement forestier, qui correspond à un milieu calme. Ces deux éléments sont révélateurs d'un ralentissement très net de la sédimentation par rapport au Préboréal. La présence du Discus rotundatus sur plus de 20 à $30 \mathrm{~cm}$ dans le $\mathrm{Lb}$ peut donc résulter pour une part d'une homogénéisation du profil comme il a été proposé pour expliquer la présence d'espèces thermophiles dans les sédiments Allerød $(\mathrm{Lg})$.

Ainsi, entre le Préboréal et le Boréal (fig. 13), la tendance générale semble être à la stabilisation de la plaine alluviale, l'essentiel de la sédimentation prenant place probablement au début de la période. Ensuite, quelques épisodes détritiques marquent le retour temporaire d'une activité fluviatile selon un rythme peut-être saisonnier ou par épisodes associés à certaines périodes plus fraîches et humides. Le matériel sableux peut provenir de l'érosion des formations alentours (dômes, fonds de chenaux, écoulements sur les versants). Les sols restent peu développés, car les apports alluviaux sont responsables d'un rajeunissement répété du profil, la durée concernée (1500 ans en moyenne) est relativement courte, la présence du couvert forestier fournit de la matière organique en permanence, ce qui favorise la nature organique du sol, les carbonates sont un frein à l'illuviation, et enfin la présence de la nappe phréatique limite la bioturbation (lombrics).

L'étude palynologique du chenal 3 donne un aperçu de la végétation à l'échelle du bassin versant bien que la végétation locale joue un rôle majeur dans l'enregistrement étudié. Le Préboréal y est caractérisé par la prédominance du pin accompagné de bouleaux puis de noisetiers. Le fond de vallée est occupé par une cariçaie puis une petite saulaie. Une grande faune composée principalement de cerfs, chevreuil et aurochs occupe l'espace. Le Boréal est marqué par le développement de la corylaie et la bonne représentation de l'orme, qui s'accompagne de l'essor du sanglier. Le fond de vallée est principalement occupé par des héliophytes, tandis que le chenal 3 est ponctuellement colonisé par une flore aquatique.

\section{4 - LE POST-BORÉAL}

D'après l'étude palynologique menée dans le chenal III (tronçon sur Warluis I, Tr. 27), la mise en place des dépôts tourbeux se poursuit à l'Atlantique ancien et au début de l'Atlantique récent (palynozone d et e). 
La vallée du Thérain connaît une phase de construction puis de dépôt de tuf détritique après le Boréal, probablement au cours de l'Atlantique. Elle n'est pas datée à Warluis mais le fonctionnement du chenal de tuf $n^{\circ} 5$ est contemporain d'une partie de la sédimentation organique. En effet, le sommet des tufs s'imbrique dans des limons argileux noirs faisant la transition entre la tourbe et les limons plastiques (Lpl, 2). Cette phase de sédimentation carbonatée est reconnue dans de nombreuses vallées du Bassin Parisien, grandes ou petites (Somme, Selle, Antoine, 1997; Marne, Lejeune et al., 2005; Mue, Lespez et al., 2008; Seine, Chaussé et al., 2008).

Les dépôts les plus récents identifiés dans le secteur étudié sont les limons plastiques ( $\mathrm{Lpl}, 2)$. Une date en sommet de tourbe $(\mathrm{T}, 3)$ sous les $\mathrm{Lpl}$ a donné $6930 \pm$ 50 BP (GrA-23551) sur le site III. L'épaisseur de dépôt est faible, de l'ordre de $40 \mathrm{~cm}$ à $1 \mathrm{~m}$. Elle est quasiment nulle sur le tuf. Cette très faible sédimentation s'explique difficilement. Il peut également y avoir un long hiatus et une courte période de sédimentation. Une étude longitudinale sur une portion plus longue de la vallée permettrait peut-être d'expliquer ce phénomène.

\section{8 - MODALITÉS D'IMPLANTATION DES SITES PRÉHISTORIQUES}

La découverte de sites du Paléolithique final et du Mésolithique dans les fonds de vallée est fréquente dans la moitié nord de la France et en particulier dans les vallées de la Somme et de ses affluents (Ducrocq, 2001; Fagnart et al., 2008). Cette position morphologique n'est pas la seule occupée puisque les populations mésolithiques se sont également installées sur les buttestémoins tertiaires ou les rebords de plateaux (Ducrocq 2001). Toutefois, dans les fonds de vallée, la conservation des sites s'avère généralement bien meilleure. La vallée du Thérain, comme les vallées du Bassin de la Somme, se caractérise en effet par un colmatage tourbeux scellant les sites contenus dans les limons sous-jacents. Dans la Somme, les tourbes présentent un développement plus important et finissent généralement par recouvrir les bas de versant. Les niveaux bien conservés du Mésolithique du début du Préboréal y sont profondément enfouis et inaccessibles comme à Amiens-Renancourt (plus de $5 \mathrm{~m}$ de profondeur, sous la nappe phréatique, Ducrocq, 2001).

L'attrait de ces zones alluviales peut s'expliquer par un milieu très diversifié et la présence de nombreuses ressources, bien que les espèces aquatiques ne semblent pas avoir été exploitées dans les sites fouillés. Ces milieux humides semblent attractifs pour les populations mésolithiques dans l'ensemble de l'Europe, que ce soit au bord d'une rivière comme aux Pays-Bas (Bos et al., 2005), ou en bord de lacs comme, par exemple, sur le site classique de Duvensee au nord de l'Allemagne (Bokelmann, 1991) ou, plus au sud, au bord du Lac de Constance (Jochim, 1998). L'accès à un cours d'eau a en outre pu favoriser les déplacements des populations lorsque le milieu s'est fermé du fait de l'extension du couvert arboré.

Un autre argument, celui de l'accès à la matière première, peut être invoqué surtout pour les occupations paléolithiques à Federmesser puisque la couverture sédimentaire et végétale sur les dômes de grave est alors moindre que durant les périodes ultérieures. La concentration VIb a par exemple fourni de nombreux éclats de débitage préservés quelques centimètres au-dessus de l'affleurement graveleux: l'absence d'outillage et l'emport d'un certain nombre de pièces issues du plein débitage plaident pour une activité spécifiquement liée à l'acquisition de matière première sur place.

$\mathrm{Au}$ début du Mésolithique, le paysage de Warluis change profondément (fig. 13). Les dômes sont recouverts par la sédimentation. La tourbification est active dans les chenaux. Les sites mésolithiques sont associés à des surfaces sèches assez proches d'un chenal. L'extension de la tourbière a provoqué par la suite un recul des installations humaines vers les zones plus hautes (site IV...). La forêt était alors plus dense, dominée par une corylaie où se développent quelques chênes, ormes et arbustes. Le sanglier était alors privilégié dans la faune chassée.

L'extension des tourbières entraîne finalement l'abandon du fond de la vallée, les hommes mésolithiques paraissant avoir déserté ces marécages devenus sans doute inhospitaliers. Il est possible qu'ils se soient alors installés plus haut sur les versants dans des zones aujourd'hui érodées.

\section{9 - CONCLUSION}

Le gisement de Warluis présente une situation exceptionnelle grâce à une tourbe diachronique qui a scellé les occupations mésolithiques et paléolithiques et à la faible sédimentation post-Boréale permettant un accès facile à l'information archéologique. Il documente les 1500 premières années du Mésolithique sur le plan morphosédimentaire, chronologique et archéologique.

Ainsi, des arguments stratigraphiques, archéologiques, malacologiques, palynologiques et des datations radiocarbone permettent d'attribuer un âge Allerød aux limons gris Lg, qui contiennent des industries du Paléolithique final à Federmesser. Sur les Lg de l'Allerød se superposent directement des apports alluviaux détritiques plus organiques bruns très bioturbés Lb qui ont été rapportés au Préboréal et au début du Boréal (ce dernier marqué par le développement de Discus rotundatus et l'extension du noisetier). Ces sédiments contiennent les vestiges mésolithiques. Entre l'Allerød et le début de l'Holocène, la plaine alluviale était occupée par un système de chenaux apparemment stables, probablement guidés par les dômes de graviers pléniglaciaires.

Les populations mésolithiques se sont installées à proximité de paléochenaux ou sur de petites éminences $\mathrm{du}$ fond de vallée. Les premières datations radiocarbone indiquent une succession d'occupations du début de l'Holocène, vers 9900 BP, jusqu'au début du Boréal 
vers 8800 BP. Les premiers résultats de l'étude archéozoologique témoignent d'une évolution des stratégies de prédation en lien avec l'évolution du couvert végétal et de la grande faune. Sur les sites du Préboréal, la prédation s'exerce sur le cerf, le chevreuil et l'aurochs tandis que l'exploitation se réoriente sur le sanglier au début du Boréal. Ceci coïncide avec la densification du couvert végétal et le boisement progressif révélés par l'analyse palynologique et les cortèges malacologiques.

\section{RÉFÉRENCES BIBLIOGRAPHIQUES}

ANTOINE P., 1997 - Modifications des systèmes fluviatiles à la transition Pléniglaciaire - Tardiglaciaire et à l'Holocène: 1'exemple du bassin de la Somme (Nord de la France). Géographie Physique et Quaternaire, 51 (1), 93-106.

ANTOINE P., FAGNART J.P., LIMONDIN-LOZOUET N., \& MUNAUT A.V., 2000 - Le Tardiglaciaire du bassin de la Somme, éléments de synthèse et nouvelles données. Quaternaire, 11 (2), $85-98$.

ANTOINE P., MUNAUT A.-V., LIMONDIN-LOZOUET N., PONEL P., \& FAGNART J.-P., 2002 - Réponse des milieux de fonds de vallée aux variations climatiques (Tardiglaciaire et Début Holocène) d'après les données du bassin de la Selle (Nord de la France). Processus et bilans sédimentaires. In J.-P. Bravard \& M. Magny (dir.), Les fleuves ont une histoire. Paléoenvironnement des rivières et des lacs français depuis 15000 ans. Ed. Errance, $15-27$

ANTOINE P., MUNAUT A.-V., LIMONDIN-LOZOUET N., PONEL P., DUPÉRON J., \& DUPÉRON M., 2003 - Response of the Selle River to climatic modifications during the Lateglacial and Early Holocene (Somme Basin - Northern France). Quaternary Science Reviews, 22, 2061-2076.

BARTHÉLÉMY L., 1985 - Réflexions sur la répartition du pollen. Conséquences pour l'archéologie. In Palynologie archéologique. Actes des journées des 25-26-27 janvier 1984, CNRS-CRA Notes et Monographies techniques, 17, 53-85.

BLONDEAU A., CAVELIER C., \& MONCIARDINI C., 1970 - Carte géologique à 1/50 000, feuille «Clermont»(XXIII-11). B.R.G.M., Orléans.

BOKELMANN K., 1991 - Duvensee, Wohnplatz 9, ein präborealzeitlicher Lagerplatz in Schleswig-Holstein. Offa, 48, 75-114.

BOS J.A.A., VAN GEEL B., GROENEWOUDT B.J., \& LAUWERIER R.C.G., 2005 - Early Holocene environmental change, the presence and disappearance of early Mesolithic habitation near Zutphen (The Netherlands). Vegetation History and Archaeobotany, 15, 27-43.

BRIDAULT A., 1997 - Chasseurs, ressources animales et milieux dans le Nord de la France de la fin du Paléolithique à la fin du Mésolithique. In J.-P. Fagnart \& A. Thevenin (dir.), Le Tardiglaciaire en Europe du nord-ouest. Actes du $119^{\mathrm{e}}$ congrès annuel des sociétés historiques et scientifiques, Amiens, octobre 1994, Ed. CTHS, Paris, 166-176.

BULLINGER-WEBER G., LE BAYON R.C., GUENAT C., \& GOBAT J.M., 2007 - Influence of some physicochemical and biological parameters on soil structure formation in alluvial soils. European Journal of Soil Biology, 43, 57-70.

CHAIX L., 1986 - Les mollusques continentaux apports à la paléoécologie et à la chronologie du Quaternaire. Revue d'Archéométrie, 10, 33-38.

CHAIX L., 1988 - Le Salève au Quaternaire : environnement et Préhistoire. Archives des Sciences, Genève, 41 (1), 159-171.

CHAUSSÉ C., LEROYER C., GIRARDCLOS O., ALLENET G., PION P. \& RAYMOND P., 2008 - Holocene history of the River Seine, Paris, France: bio-chronostratigraphic and geomorphological evidence from the Quai-Branly. The Holocene, 18 (6), 967-980.

DUCROCQ T., 2001 - Le Mésolithique du bassin de la Somme. Insertion dans un cadre morpho-stratigraphique, environnemental et chronoculturel. Publications du CERP, 7, $255 \mathrm{p}$.

DUCROCQ T., BRIDAULT A., \& COUTARD S., 2008 - Le gisement mésolithique de Warluis: approche préliminaire. In J.-P. Fagnart, A. Thevenin, T. Ducrocq, B. Souffi \& P. Coudret (dir.), Le début du Mésolithique en Europe du Nord-Ouest. Actes de la Table ronde d'Amiens, 9 et 10 octobre 2004, Mémoire de la Société Préhistorique Française, 45, 85-106
FAGNART J.-P., 1997 - La fin des temps glaciaires dans le Nord de la France. Mémoire de la Société Préhistorique Française, 24, 270 p.

FAGNART J.P., \& COUDRET P., 2000 - Données récentes sur la Tardiglaciaire du bassin de la Somme. In G. Pion (dir.), Le Paléolithique supérieur récent: nouvelles données sur le peuplement et l'environnement. Actes de la table Ronde de Chambéry, 12-13 mars 1999, Mémoire de la Société Préhistorique Française, 28, 113-126.

FAGNART J.-P., COUDRET P., \& SOUFFI B., 2008 - Les occupations mésolithiques du gisement de Saleux. In J.-P. Fagnart, A. Thevenin, T. Ducrocq, B. Souffi \& P. Coudret (dir.), Le début du Mésolithique en Europe du Nord-Ouest. Actes de la Table ronde d'Amiens, 9 et 10 octobre 2004, Mémoire de la Société Préhistorique Française, 45, 107-133

HAVINGA A.J., 1984 - A 20-years experimental investigation into the differential corrosion susceptibility of pollen and spores in various soil types. Pollen et Spores, XXVI (3-4), 541-558.

HEIM J., 1970 - Les relations entre les spectres polliniques récents et la végétation actuelle en Europe occidentale. Thèse d'Etat, Université de Louvain (Belgique), 1 vol., 181 p.

KERNEY M.P., CAMERON R.A.D, \& JUNGBLUTH J.H., 1983 Die Landschnecken Nord-und Mitteleuropas. Paul Parey, Hamburg und Berlin, $384 \mathrm{p}$

JOCHIM M., 1998 - A hunther-gatherer landscape: Southwest Germany in the Late Paleolithic and Mesolithic. Plenum Press, NewYork, $247 \mathrm{p}$.

LEJEUNE Y., PASTRE J.-F., ARCAY D., AUBRY L., CAMERLYNCK C., CONFALONIERI J., LANCHON Y., VERGNAUD D., \& VISSAC C., 2005 - Variabilité de l'enregistrement alluvial holocène : l'exemple du méandre de la Haute-île (Vallée de la Marne, Bassin parisien), premiers résultats. Quaternaire, 16 (4), 299-313.

LESPEZ L., CLET-PELLERIN M., LIMONDIN-LOZOUET N. PASTRE J.-F., FONTUGNE M., \& MARCIGNY C., 2008 - Fluvial system evolution and environmental changes during the Holocene in the Mue valley (Western France). Geomorphology, 98, 55-70.

LEROYER C., 1997 - Homme, Climat, Végétation au Tardi-et-Postglaciaire dans le Bassin parisien: apports de l'étude palynologique des fonds de vallée. Thèse de Doctorat, Université de Paris I, 2 vol. 786 p., 212 fig.

LEROYER C., 2004 - L'anthropisation du Bassin parisien du VII ${ }^{\mathrm{e}}$ au IV millénaire d'après les analyses polliniques de fonds de vallées: mise en évidence d'activités agro-pastorales très précoces. In H. Richard (dir.), Néolithisation précoce. Première trace d'anthropisation du couvert végétal à partir des données polliniques. Collection Annales littéraires, série Environnement, Sociétés et Archéologie, Presses Universitaires de Franche-Comté, Besançon, 7, 11-27.

LEROYER C., 2006a - L'environnement végétal des sites : les données de la palynologie. In F. Malrain \& E. Pinard (dir.), Les sites laténiens de la moyenne vallée de l'Oise du $v^{e}$ au $I^{e r}$ s. avant notre ère. Contribution à l'Histoire de la société gauloise. Revue archéologique de Picardie, $n^{\circ}$ sp. 23, 34-42.

LEROYER C., 2006b - L'impact des groupes néolithiques du Bassin parisien sur le milieu végétal: évolution et approche territoriale d'après les données polliniques. In P. Duhamel (dir.), Impacts interculturels au Néolithique moyen. Du terroir au territoire: sociétés et espaces. Actes du $25^{\mathrm{e}}$ colloque interrégional sur le Néolithique, Dijon 2001. Revue Archéologique de l'Est, suppl. 25, 133-150.

LEROYER C., \& ALLENET G., 2002 - L'enregistrement pollinique du Tardiglaciaire dans le centre du Bassin Parisien. In Habitats et peuplements tardiglaciaires du Bassin parisien. Rapport non publié, Service Régional de l'Archéologie d'Ile-de-France, 35-53.

LIMONDIN N., 1995 - Late-glacial and Holocene malacofaunas from archaeological sites in the Somme Valley (North France). Journal of Archaeological Science, 22, 683-698.

LIMONDIN-LOZOUET N., 1997 - Mollusca in archaeological context: tools for palaeoenvironmental reconstructions. The example of "Le Closeau", a prehistoric site in the Seine valley (France). Heldia, 4 (5), 166-171.

LIMONDIN-LOZOUET N., 1998 - Successions malacologiques du Tardiglaciaire Weichsélien: corrélations entre séries du Nord de la France et du Sud-est de la Grande-Bretagne. Quaternaire, 9, 217-225

LIMONDIN-LOZOUET N., 2002 - Impact des oscillations climatiques du Tardiglaciaire sur l'évolution des malacofaunes de fond de vallée en Europe du Nord-Ouest. In H. Richard \& A. Vignot (eds.), Equilibres et ruptures dans les écosystèmes depuis 20000 ans en Europe de l'Ouest. Presses Universitaires Franc-Comtoises, Besançon, 45-51.

LIMONDIN-LOZOUET N., \& ANTOINE P., 2001 - Palaeoenvironmental changes inferred from malacofaunas in the Lateglacial and Early Holocene fluvial sequence at Conty (Northern France). Boreas, 30, 148-164. 
LIMONDIN-LOZOUET N., BRIDAULT A.,LEROYER C.,PONEL P., ANTOINe P., CHAUSSÉ C., MUNAUlt A.V. \& PASTRE J.-F., 2002 - Evolution des écosystèmes de fond de vallée en France septentrionale au cours du Tardiglaciaire: l'apport des indicateurs biologiques. In J.P. Bravard \& M. Magny (eds.), Les fleuves ont une histoire. Paléo-environnement des rivières et des lacs français depuis 15000 ans. Paris, Errance, 45-62.

LIMONDIN-LOZOUET N., \& PREECE R.C., 2004 - Molluscan successions from the Holocene tufa of St-Germain-le-Vasson in Normandy, France. Journal of Quaternary Science, 19 (1), 55-71.

LIMONDIN-LOZOUET N., GAUTHIER A., \& PREECE R., 2005 - Enregistrement des biocénoses de la première moitié de l'Holocène en contexte tufacé à Saint-Germain-le Vasson (Calvados). Quaternaire, 16 (4), 265-271.

MANGERUD J.,ANDERSEN S.T., BERGLUND B.E., \& DONNER J.J., 1974 - Quaternary stratigraphy of Norden, a proposal for terminology and classification. Boreas, 3, 109-128.

MEYRICK R.A., 2000 - Holocene molluscan faunal history and environmental change from a tufa at Direndall, Luxembourg. Bulletin de la Société Préhistorique Luxembourgeoise, 22, 55-75.

MEYRICK R.A., 2001 - The development of terrestrial mollusc faunas in the "Rheinland region" (western Germany and Luxemboug) during the Lateglacial and Holocene. Quaternary Science Reviews, 20, $1667-1675$.

MEYRICK R.A., \& PREECE R.C., 2001 - Molluscan successions from two Holocene tufas near Northampton, English Midlands. Journal of Biogeography, 28, 77-93.

PASTRE J.-F., FONTUGNE M., KUZUCUOGLU C., LEROYER C., LIMONDIN-LOZOUET N., TALON M., \& TISNERAT N., 1997 - L'évolution tardi- et postglaciaire des lits fluviaux au nord-est de Paris (France). Relations avec les données paléoenvironnementales et l'impact anthropique sur les versants. Géomorphologie: relief, processus, environnement, 4, 291-312.

PASTRE J.-F., LEROYER C., LIMONDIN-LOZOUET N., CHAUSSÉ C., FONTUGNE M., GEBHARDT A., HATTé C., \& KRIER V., 2000 - Le Tardiglaciaire des fonds de vallée du Bassin Parisien (France). Quaternaire, 11, 107-122.

PASTRE J.-F., LEROYER C., LIMONDIN-LOZOUET N., ORTH P., CHAUSSE C., FONTUGNE M., GAUTHIER A., KUNESCH S., LEJEUNE Y., \& SAAD M.-C., 2002 - Variations paléoenvironnementales et paléohydrologiques durant les 15 derniers millénaires: les réponses morphosédimentaires des vallées du Bassin Parisien (France). In J.-P. Bravard \& M. Magny (eds.), Les fleuves ont une histoire. Paléoenvironnement des rivières et des lacs français depuis 15000 ans. Ed. Errance, Paris, 29-44.

PASTRE J.-F., LIMONDIN-LOZOUET N., LEROYER C., PONEL P., \& FONTUGNE M., 2003 - River system evolution and environmental changes during the Lateglacial in the Paris Basin. Quaternary Science Reviews, 22, 2177-2188.
PEDLEY H.M., 1990 - Classification and environmental models of cool freshwater tufas. Sedimentary Geology, 68, 143-154.

PENTECOST A., \& VILES H., 1994 - A review and reassessment of travertine classification. Géographie Physique et Quaternaire, 48 (3), 305-314.

PONEL P., COOPE R., ANTOINE P., LIMONDIN-LOZOUET N., LEROYER C., MUNAUT A.-V., PASTRE J.-F., \& GUITER F., 2005 - Lateglacial Palaeoenvironments and Palaeoclimates from Conty and Houdancourt, Northern France, reconstructed from Beetle remains. Quaternary Science reviews, 24, 2449-2465.

PREECE R.C., 1997 - The spatial response of non-marine Mollusca to past climate changes. In B. Huntley et al. (eds.), Past and future rapid environmental changes: the spatial and evolutionary responses of terrestrial biota. NATO ASI, series 47, 163-177.

PREECE, R.C., \& DAY, S.P., 1994 - Comparison of Post-glacial molluscan and vegetational successions from a radiocarbondated tufa sequence in Oxfordshire. Journal of Biogeography, 21, 463-478.

PREECE R.C., \& BRIDGLAND D.R., 1999 - Holywell Coombe, Folkestone: a 13,000 year history of an English chalkland valley. Quaternary Science Reviews, 18, 1075-1125.

PUISSÉGUR J.-J., 1976 - Mollusques continentaux quaternaires de Bourgogne. Mémoires Géologiques de l'Université de Dijon, 3 , Doin, Paris, $241 \mathrm{p}$.

RASMUSSEN S.O., ANDERSEN K.K., SVENSSON A.M., STEFFENSEN J.P., VINTHER B.M., CLAUSEN H.B., SIGGAARD-ANDERSEN M.-L., JOHNSEN S.J., LARSEN L.B., DAHL-JENSEN D., BIGLER M., RÖTHLISBERGER R., FISCHER H., GOTO-AZUMA K., HANSSON M.E., \& RUTH U., 2006 - A new Greenland ice core chronology for the last glacial termination. Journal of Geophysical Research, 111, D06102.

RASMUSSEN S.O.,VINTHER B.M., CLAUSEN H.B., \& ANDERSEN K.K., 2007 - Early Holocene climate oscillations recorded in three Greenland ice cores. Quaternary Science Reviews, 26, 1907-1914.

REILLE M., 1990 - Leçons de Palynologie et d'analyse pollinique. Paris, C.N.R.S., 206 p.

SIIRA-PIETIKÄINEN A., PENTTINEN R., \& HUHTA V., 2008 Oribatid mites (Acari: Oribatida) in boreal forest floor and decaying wood. Pedobiologia, 52 (2), 111-118.

VALENTIN B., FOSSE G., \& BILLARD C., 2004 - Aspects et rythmes de l'azilianisation dans le Bassin parisien. Caractérisation de l'industrie lithique recueillie au Cornet (locus 33) à Ambenay, Eure. Gallia Préhistoire, 46, 171-209. 